\title{
Correlating molecular morphology with optoelectronic function in solar cells based on low band-gap copolymer:fullerene blends
}

Cite this: J. Mater. Chem. C, 2013, 1, 7266

Received 27th June 2013 Accepted 20th September 2013 DOI: $10.1039 / \mathrm{c} 3 \mathrm{tc} 31235 f$ www.rsc.org/MaterialsC

\author{
Tao Wang, ${ }^{*}$ Andrew J. Pearson and David G. Lidzey*
}

We review recent progress in the development of organic bulk heterojunction (BHJ) solar cells employing donor-acceptor copolymers as the electron-donor and fullerene derivatives as the electron-acceptor. We discuss the role of the donor and acceptor moieties, side-chains, bridging units and atomic substitutions of the copolymers on their optoelectronic functionality. The physical properties, e.g. molecular conformation, miscibility, phase-separated lateral and vertical morphology, of various photovoltaic blends prepared via solution casting and post-treatments are reviewed and correlated with photovoltaic device performance. Factors influencing the morphological stability of polymer:fullerene BHJ thin-films are briefly discussed. Finally, we address the use of thin organic interlayers to increase the efficiency of BHJ solar cells.

\section{Introduction}

Bulk heterojunction (BHJ) organic photovoltaic (OPV) devices employing conjugated polymers as electron donors and fullerene derivatives as electron acceptors convert the energy of sunlight into electrical current using the photovoltaic effect. ${ }^{\mathbf{1 , 2}}$ The ability to process an OPV device partly from solution makes them a promising low-cost technology for solar energy

Department of Physics and Astronomy, University of Sheffield, Sheffield, S3 7RH, UK. E-mail: t.wang@hotmail.com; d.g.lidzey@sheffield.ac.uk conversion. The power conversion efficiency (PCE) of the best performing OPV devices has in recent years approached that of dye-sensitized solar cells and is comparable with established PV technologies based on amorphous silicon. Indeed, BHJ OPV devices employing donor-acceptor (D-A) copolymers in the photoactive layer currently yield PCEs exceeding $9 \%$ in single junction cells ${ }^{3}$ and over $10 \%$ in tandem solar cells. ${ }^{4}$

D-A copolymers - also called push-pull copolymers - consist of alternating electron-rich (D) and electron-deficient (A) moieties along a conjugated backbone. ${ }^{5-9}$ Such copolymers often have a relatively low optical band-gap due to the

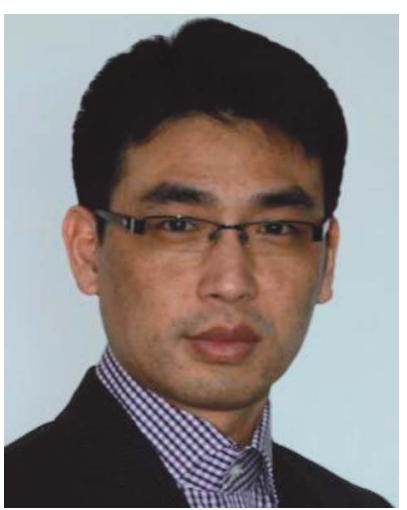

Tao Wang received his B.Sc. in Polymer Materials (2002) and M.Sc. in Materials Science (2005). He obtained his Ph.D. in Soft Condensed Matter Physics from the University of Surrey (UK) in Feb. 2009, under the supervision of Prof. Joe Keddie. He then took a post-doc research associate position in the same group until Oct. 2009 when he moved to the Department of Physics and Astronomy at the University of Sheffield (UK). At Sheffield, he works with Prof. Richard Jones and Prof. David Lidzey on morphology characterization and device optimization of organic solar cells. His research interests are polymer physics and polymer electronics.

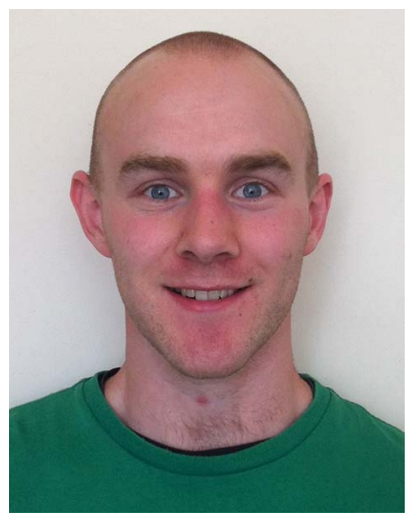

Andrew Pearson received his MSci (Physics, 2008) from the University of Nottingham (UK). Thereafter, he joined the research group of Professor David Lidzey at the University of Sheffield (UK) to study for his Ph.D. in Organic Semiconductor Physics, which was awarded in 2012. His post-graduate research focussed on the rational understanding of common processing techniques used in the fabrication of polymer:fullerene blend films for solar cell applications. Upon graduating, he has stayed at Sheffield as a post-doctoral research associate, to continue his work on the structural and spectroscopic characterisation of polymer:fullerene blend films. 
hybridization of molecular orbital levels; an effect that leads to significant electron delocalization and intramolecular charge transfer. ${ }^{6}$ The synthesis of D-A copolymers therefore offers a route to achieve efficient light harvesting of the solar spectrum. The electrochemical and optoelectronic properties of a copolymer can be tuned by modifying its molecular structure; for example through the use of different heterocycles that are either electron-rich or electron-deficient, or via the size and position of solubilising side-groups. These parameters will have a significant impact on the nanoscale structure of the copolymer in the solid-state - for example its molecular packing and relative crystallinity, with such properties consequently affecting polymer miscibility with other materials. In a $\mathrm{BHJ}$ thin-film, a complex nano- and meso-scale morphology exists between the copolymer and the electron acceptor that, in turn, influences the photocurrent generation efficiency of the system when incorporated into a functional PV device. This review aims to cover such aspects, and attempts to provide an empirical guide into the chemical design of new materials together with rational processing protocols to create high performance $\mathrm{D}-\mathrm{A}$ polymer:fullerene solar cells.

\section{Molecular packing, mixing and phase separation in D-A copolymer:PCBM photovoltaic blends}

When fabricating an OPV device, the electron donor (e.g. a conjugated polymer) and the acceptor (typically a fullerene derivative such as $\mathrm{PC}_{61} \mathrm{BM}$ or $\mathrm{PC}_{71} \mathrm{BM}$ ) are often dissolved in a common solvent or co-solvent mixture. On casting the solution to form a thin-film, a partial de-mixing of the blend components triggered by solvent evaporation occurs in order to minimize the free energy of the system. Other self-organization processes, such as crystallization, aggregation and self-assembly, may also occur as the casting solvent evaporates. The final structure of the thin-film will be determined by a number of parameters including the relative miscibility between the materials, the

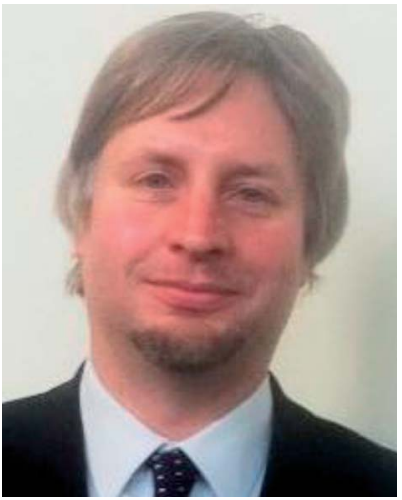

Prof. David Lidzey studied for a B.Sc. in Physics at the University of Birmingham (1985-1988). After working for two years at Kodak Ltd. in Harrow in the Analytical Department, he returned to Birmingham in 1990 to study for a Ph.D. in Molecular Electronics. After graduation in 1994, he moved to the University of Sheffield to undertake postdoctoral research in the area of polymer light emitting diodes. He has subsequently held research Fellowships from both Lloyds of London and the UK EPSRC. He was promoted to a personal chair in 2007 and his current research interests include the use of organic semiconductors in photonics and optoelectronics. He is co-founder and Chairman of the organic electronics company Ossila Ltd. drying dynamics of the solution and the surface properties of the substrate onto which the film is cast. A variety of complementary experimental techniques have been used to probe the structural or optoelectronic properties of the blend thin-film in order to understand the impact of different materials and processing conditions on OPV device performance and stability. ${ }^{\mathbf{1 0 - 1 2}}$ In situ probes of molecular organization and phase separation processes have also been used to unravel the mechanisms by which nanostructure develops during the film solution-deposition process $^{13-15}$ and during post-deposition treatments such as thermal annealing ${ }^{16-18}$ and solvent-vapor annealing. ${ }^{19}$

Some D-A copolymers are semi-crystalline, although they do not have the same high degree of crystallinity that is observed in homopolymers such as poly(3-hexylthiophene) (P3HT). Nevertheless, the ability of D-A copolymers to selforganize can be tuned through control of molecular structure. Various D-A copolymers utilizing thieno[3,4-c]pyrrole-4,6dione (TPD), diketo-pyrrole-pyrrole (DPP), bithiazole (BTz), naphtho-bisthiadiazole (NTz) and benzothiadiazole (BT) moieties as electron-accepting units have all exhibited some degree of crystallization. ${ }^{20-24}$ For example, the crystalline character of benzo[1,2- $\left.b: 4,5-b^{\prime}\right]$ dithiophene (BDT) based D-A copolymers can be tuned by varying the number of nitrogen atoms in the acceptor unit. ${ }^{25}$ This is exemplified in the $2 \mathrm{D}$ grazing-incidence wide-angle X-ray scattering (GIWAXS) images shown in Fig. 1, where it can be seen that diffraction peaks are most intense in the out-of-plane direction, indicating a predominantly edge-on orientation of the copolymers relative to the substrate plane. ${ }^{25}$ Here, the (010) peak located in the in-plane direction originates from $\pi-\pi$ stacking between polymer backbones (i.e. $\pi-\pi$ stacking is directed parallel to the substrate). With an increasing number of nitrogen atoms in the acceptor unit, second and third order reflections of the lamellar scattering features appear and become more pronounced. The lamellar spacing $\left(d_{1}\right)$ and $\pi-\pi$ stacking distance $\left(d_{2}\right)$ are also dependent on the number of nitrogen atoms in the acceptor unit, having $d_{1}\left(d_{2}\right)$ values of $1.61(0.42), 1.72(0.37)$ and $1.78 \mathrm{~nm}$ $(0.36 \mathrm{~nm})$ in polymers containing 0,1 and 2 nitrogen atoms respectively. In later sections, we will discuss further the effect of D-A molecular structure on molecular packing.

Many other D-A copolymers are predominantly amorphous yet exhibit weak $\pi-\pi$ stacking in the solid state. For example, $\pi-\pi$ stacking in the polymer PTB1 (which is based on alternating thieno[3,4- $b]$ thiophene and benzodithiophene units) is evidenced by a 'crescent' observed at $q=1.71 \AA^{-1}\left(d_{2}=3.7 \AA\right)$ in the out-of-plane direction of the $2 \mathrm{D}$ grazing-incidence $\mathrm{X}$-ray scattering patterns, as shown in Fig. 2a. ${ }^{26,27}$ This suggests a "face-on" orientation of $\pi-\pi$ stacking -i.e. the plane of the PTB1 backbone is oriented parallel to the underlying substrate. A diffraction ring is also observed at $q=0.23 \AA^{-1}\left(d_{1}=27.3 \AA\right)$ that results from lamellar spacing between neighboring PTB1 backbones separated by their side-groups. The ability of conjugated polymers to preferentially $\pi-\pi$ stack "face-on" with respect to the substrate is considered to facilitate efficient charge transport in an OPV device. ${ }^{27}$ Although PTB1 is an amorphous copolymer, the out-of-plane space-charge limited current (SCLC) charge mobility of PTB1 $\left(\sim 4.5 \times 10^{-4} \mathrm{~cm}^{2} \mathrm{~V}^{-1}\right.$ $\left.\mathrm{s}^{-1}\right)$ is higher than that of P3HT $\left(\sim 2.7 \times 10^{-4} \mathrm{~cm}^{2} \mathrm{~V}^{-1} \mathrm{~s}^{-1}\right)$; an 

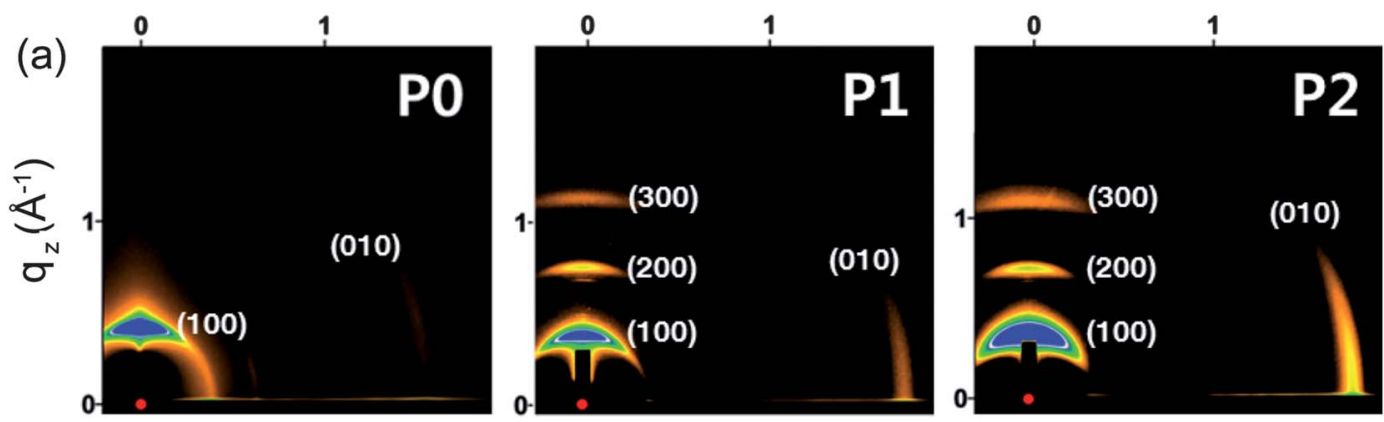

$$
q_{x y}\left(\AA^{-1}\right)
$$

(b)

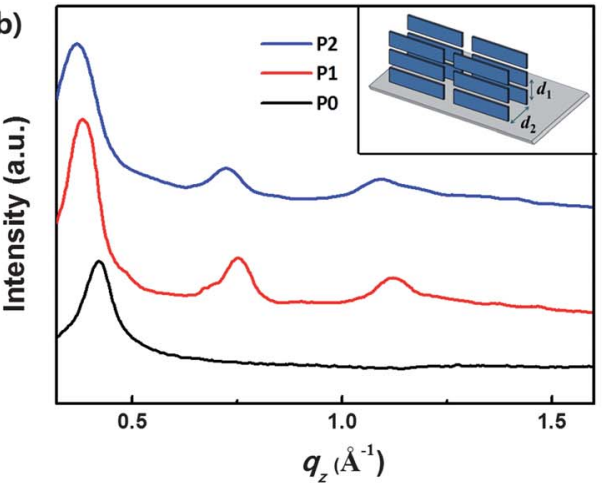

(c)

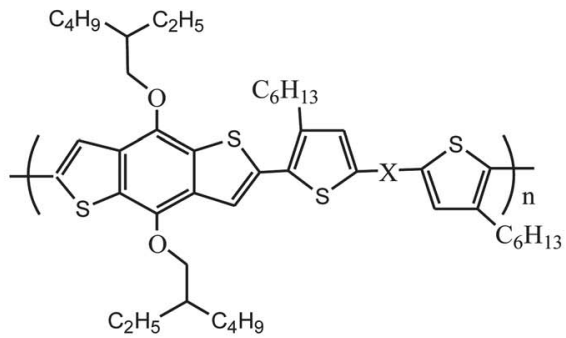

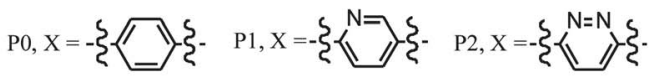

Fig. 1 (a) 2D-GIXS images of PO, P1 and P2 films after thermal annealing; (b) out-of-plane line cuts of GIXS. Inset: schematic illustration of the edge-on orientation of the polymers with the backbone perpendicular to the substrate. The interchain lamellar spacing and the $\pi-\pi$ stacking distances are labeled as $d_{1}$ and $d_{2}$, respectively. (c) Chemical structure of BDT-based D-A copolymers P0, P1 and P2 having 0, 1, or 2 nitrogen atoms in the acceptor units. Figure reprinted from ref. 25, Copyright $\odot$ 2012, American Chemical Society.
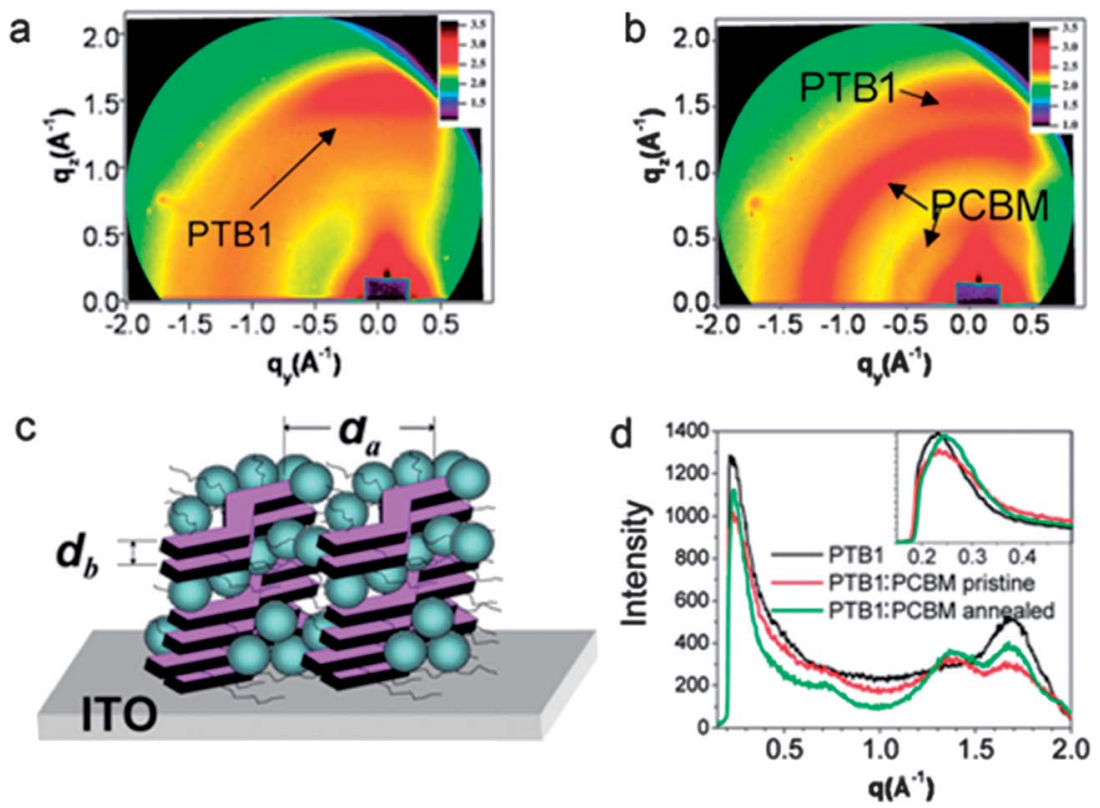

Fig. 2 GIWAXS images of (a) pure PTB1 and (b) a PTB1:PC ${ }_{61}$ BM $1: 1$ blend. (c) Schematic illustration of the orientation of the polymer backbone and side-chains in a PTB1:PC ${ }_{61}$ BM blend. (d) X-ray intensity recorded in the out-of-plane direction of a 2D GIWAXS image. Figure reprinted from ref. 26, Copyright $\odot$ 2010, American Chemical Society.

effect that may well result from the fact that P3HT chains preferentially stack "edge-on" with respect to a substrate. ${ }^{28}$ When PTB1 is cast into a photovoltaic blend with $\mathrm{PC}_{61} \mathrm{BM}$, there are negligible changes to the lamella spacing or the $\pi-\pi$ stacking distance (see Fig. $2 \mathrm{~b}$ and d). It can be seen however that the intensity of $\pi-\pi$ X-ray scatter undergoes a relative reduction 
on mixing with $\mathrm{PC}_{61} \mathrm{BM}$; a result explained on the basis that intermixing between the polymer and PCBM reduces long-range order within the polymer-rich phase of the film. ${ }^{26}$

Early research on the morphology of BHJ polymer:fullerene photovoltaic blends often described the nanostructure in terms of a bi-continuous network of domains, composed of sharply defined regions of pure polymer and pure-fullerene that exist as a result of spontaneous phase-separation between the components. ${ }^{29,30}$ A number of studies over the last few years have shown, however, that there are at least three phases in a polymer:fullerene photovoltaic blend; a pure polymer phase, a pure fullerene phase and a mixed phase of the two different materials. ${ }^{31,32}$ In each of the pure phases, crystalline and amorphous regions may also co-exist, ${ }^{33}$ with the extent of the crystallization dependent on the nature of molecular packing and the solution-casting process which impacts on the kinetics of molecular packing. Fig. 3 illustrates a schematic of the various different phases believed to exist in a semi-crystalline and an amorphous polymer:fullerene blend. At the molecular level, the intimately mixed phase in amorphous copolymer:fullerene blends such as PTB7 or PCDTBT with $\mathrm{PC}_{71} \mathrm{BM}$ is best described as an amorphous solid solution. Resonant Soft $\mathrm{X}$-ray Scattering (R-SoXS) studies have shown that $\mathrm{PC}_{71} \mathrm{BM}$ is soluble in the mixed phase of PTB7: $\mathrm{PC}_{71} \mathrm{BM}$ blend film at a concentration of up to $\sim 30 \%$. $^{34}$

In some semi-crystalline copolymer:fullerene blends, X-ray scattering has revealed that fullerene molecules are able to intercalate between polymer chains. $^{32}$ For example, in a pBTTT:PCBM thin-film blend, GIWAXS measurements have shown that the lamellar packing distance between pBTTT backbones increased from $21 \AA$ (in pure pBTTT) to $\sim 30 \AA$ in a $1: 4$ polymer:fullerene blend. ${ }^{32}$ This increase was proposed to originate from an intercalation of the fullerene molecules into the polymer crystal, forming a highly ordered bimolecular crystal. Although molecular mixing of fullerenes may in principle disrupt the packing of an amorphous polymer, such effects are often difficult to confirm using X-ray diffraction techniques alone due to the low level of polymer crystallinity. ${ }^{35}$ The influence of fullerene derivative structure on the morphology and photovoltaic performance of copolymer:fullerene blend films will be discussed in detail later in this Review.

Recent studies have identified the importance of the intermixed phases of PCBM and polymer on the optoelectronic processes of solar cells..36,37 These finely mixed polymer/ fullerene phases are believed to improve the yield of free charge

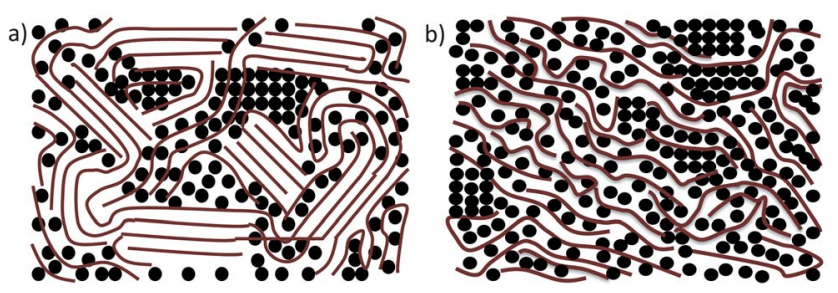

Fig. 3 A schematic illustration of the different phases in a blend of (a) a semicrystalline polymer and PCBM and (b) an amorphous polymer and PCBM. carriers within a $\mathrm{BHJ}$ film. In addition, the formation of appropriately sized percolating pure phases permits the relatively efficient transport of charge carriers towards the solar cell electrodes. ${ }^{36,37}$ For high performance solar cells, it is desirable that the intermixed phase co-exists with the relatively pure phases, rather than the formation of a one-phase system comprised of a solid solution. ${ }^{37}$

\section{The impact of molecular structure of $D-A$ copolymers on energy level, band-gap, charge mobility, molecular packing and photovoltaic device performance}

\subsection{Effects of donor and acceptor moiety}

Upon photoexcitation of a conjugated polymer, a minimum energy offset between the LUMO level of the polymer donor and the PCBM acceptor of approximately $0.3 \mathrm{eV}$ has often been deemed necessary to efficiently drive electron transfer to the fullerene. ${ }^{38,39}$ For example, taking $\mathrm{PC}_{61} \mathrm{BM}$ as the acceptor (having a LUMO level at $-4.2 \mathrm{eV}$ ), this implies a minimum LUMO level of the polymer donor of $-3.9 \mathrm{eV}$ is necessary to permit charge transfer to the $\mathrm{PC}_{61} \mathrm{BM}$ (Fig. 4). ${ }^{5,7}$ In a photovoltaic device, a deeper HOMO level of the polymer donor will help increase the device $V_{\text {oc }}$; a concept confirmed by a statistical review. ${ }^{7}$ However, $V_{\text {oc }}$ is reduced when the HOMO level is lower (i.e. closer to vacuum) than $-5.7 \mathrm{eV}^{7}$ As $\mathrm{PC}_{61} \mathrm{BM}$ has a low extinction coefficient at visible and near-IR wavelengths, the polymer donor is the main light-absorbing component in a photovoltaic blend. The same statistical summary shows that reducing the D-A copolymer bandgap results in a higher $J_{\mathrm{sc}}$ as more of the sun's radiation can be harvested. However, once the bandgap falls below $1.3 \mathrm{eV}$, the $J_{\text {sc }}$ starts to fall. ${ }^{7}$ It appears therefore that a bandgap of 1.4 to $1.5 \mathrm{eV}$ is ideal for efficient sunlight absorption and subsequent photocurrent generation. Consequently, in $\mathrm{BHJ}$ thin-films using $\mathrm{PC}_{61} \mathrm{BM}$ as an electron acceptor the optimum HOMO level of the polymer should be around $-5.4 \mathrm{eV}$.

For D-A copolymers, the energies of the molecular orbital levels and the corresponding band-gap are primarily determined by the chemical and structural composition of the conjugated

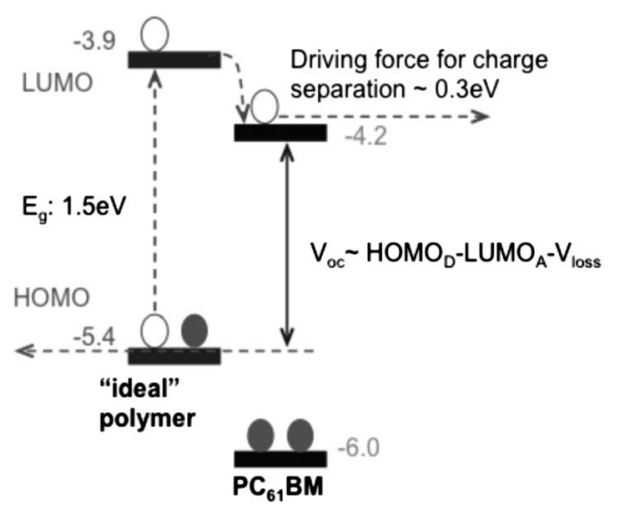

Fig. 4 Schematic energy level alignments between an "ideal polymer" donor and a $\mathrm{PC}_{61} \mathrm{BM}$ acceptor. 
backbone, with the HOMO (LUMO) level generally determined by that of the electron donating (accepting) moiety. ${ }^{40}$ This architecture permits the HOMO and LUMO levels of the copolymer to be defined almost independently of one other. Note however that the size, structure and position of solubilising side-groups on the co-polymer backbone also provide an opportunity to fine-tune the position of these energy levels. A large number of D-A copolymers have been synthesized by employing different electron-rich and electron-deficient moieties along the backbone and by rational control over sidechains, bridging units and substituents along the repeating units of a D-A conjugated copolymer. ${ }^{5-9}$ Examples of donor and acceptor moieties are shown in Fig. 5. Here, electron-rich heterocycles such as fluorene, carbazole, cyclopentadithiophene (CPD), naphtho[2,1-b:3,4- $\left.b^{\prime}\right]$-dithiophene (NDT), benzo[1,2- $\left.b: 4,5-b^{\prime}\right]$ dithiophene (BDT), dithieno[3,2$\left.f: 2^{\prime}, 3^{\prime}-h\right]$ quinoxaline (QDT), thiophene-phenylene-thiophene (TPT) dithieno[3,2-b:2', $\left.3^{\prime}-d\right]$-silole (DTS) indacenodithiophene (IDT) have been used as the donor moieties, with electrondeficient heterocycles such as 2,1,3-benzothiadiazole (BT), 4,7-di-2-thienyl-2,1,3-benzothiadiazole (DTBT), diketopyrrolopyrrole (DPP), thiadiazolo[3,4-c]pyridine (PyT), thieno[3,4-c]pyrrole-4,6-dione (TPD), dithieno[3,2-f: $\left.: 2^{\prime}, 3^{\prime}-h\right]$ quinoxaline (DTQ) employed as the acceptor. Synthesizing D-A copolymers with characteristically "weak donor" and "strong acceptor" moieties has been demonstrated to create semiconductors having relatively deep HOMO levels and narrow band-gaps. ${ }^{7}$ Here, the "weak donor" reduces the D-A polymer HOMO level whilst the "strong acceptor" reduces the energy band-gap via intra-molecular charge transfer (ICT) behavior. ${ }^{7}$ We refer the interested reader to the literature for an empirical comparison of the electron donating ability of various donor units, as well as examples of strong acceptors. ${ }^{7}$
It is important to acknowledge that the use of a copolymer:PCBM blend having (in theory) 'ideal' HOMO and LUMO levels may not necessarily translate into a high-performance OPV device. Recombination of charge carriers, either via germinate or non-germinate processes, will act to reduce the maximum achievable $V_{\mathrm{oc}}$ and $J_{\mathrm{sc}}$ of a device. Such effects can in principle be influenced by the presence of non-ideal active layer morphology. Practically therefore, an ideal polymer should also exhibit favourable miscibility and undergo phase separation at appropriate length-scales with an electron acceptor. It should also have a high and balanced charge carrier mobility (i.e. comparable to charge transport between fullerene molecules) in a BHJ blend thin-film. Furthermore, in order to minimize oxidation of the copolymer, the HOMO level should also be sufficient deep $(\leq-5.27 \mathrm{eV})$ to ensure operational stability of a working OPV device. Such requirements for fabricating an efficient OPV device indicate the existence of a highly complex 'parameter-space' in which many different co-polymers can be conceived. In the following sections we examine these effects in a number of different copolymer families.

\subsection{Effects of side-chain distribution and structure}

The addition of side chains to a co-polymer backbone - either grafted onto the donor and/or the acceptor moieties - will influence its physical properties such as solubility and propensity to undergo self-organization. Side-chains will also modify the electronic (electrochemical) properties of the copolymer which - when blended with an electron acceptor in a BHJ thin-film - will consequently affect the optoelectronic properties of the resultant device. ${ }^{41-43}$ During the design and synthesis of a new copolymer, the choice of side-chains becomes an important consideration as it is necessary to
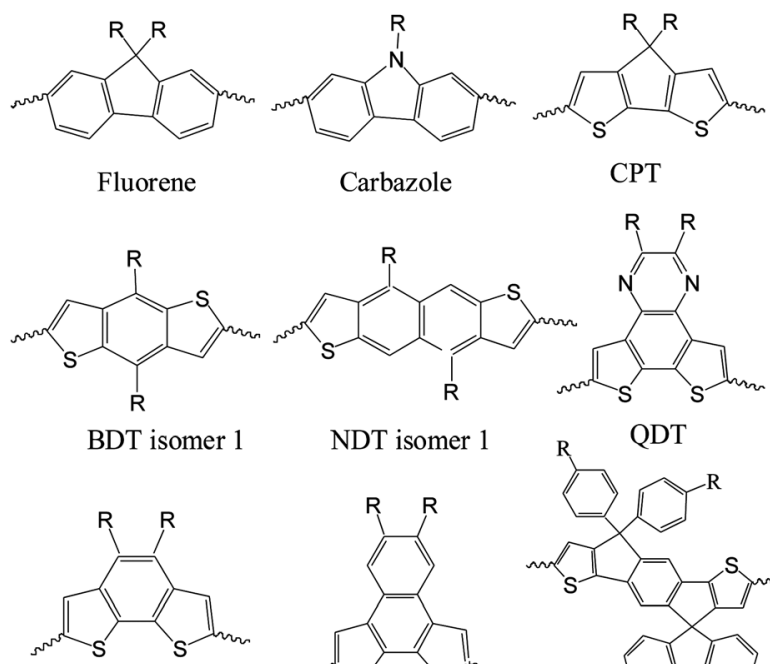

BDT isomer 2<smiles>[R]c1c2cc(C)sc2cc2c([R])c3cc(C)sc3cc12</smiles>

NDT isomer 1

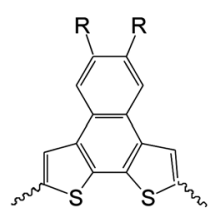

NDT isomer 1

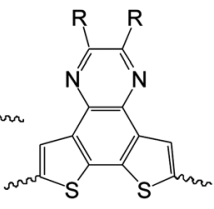

QDT

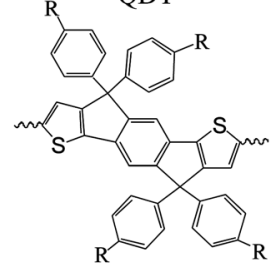

TPT

Electron-donating units

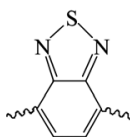

BT

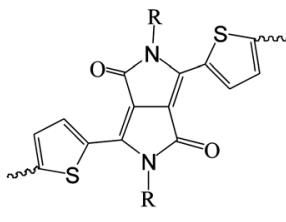

DPP

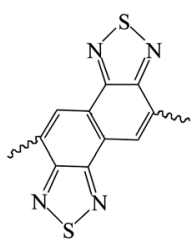

NT

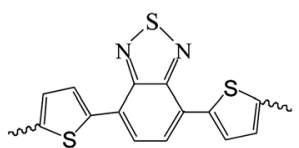

DTBT

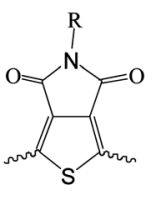

TPD

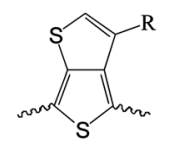

TT
Electron-accepting units

Fig. 5 Chemical structures of selected electron-donating and electron-accepting units used in D-A copolymers. 
optimise solubility (and therefore processability) with optoelectronic properties of the resultant semiconductor.

The length and shape of the side-chains in the D-A copolymer PDTSTPDs have been found to affect the self-assembly and packing of the polymer in photovoltaic blend thin-films. ${ }^{44}$ Indeed by increasing the length of alkyl chains attached to the TPD unit of copolymer PDTSTPD, it was possible to improve material solubility and facilitate the formation of lamellar structures within a blend thin-film. ${ }^{44}$ When blended with $\mathrm{PC}_{71} \mathrm{BM}$ in an $\mathrm{BHJ}$ thin-film, this structural characteristic of PDTSTPD permitted the fabrication of OPV devices having a relatively high power conversion efficiency (PCE) of $7.5 \% .{ }^{44}$ In other studies, the effect of butyl (Bu), hexyl (He), octyl (Oc), and 2-ethylhexyl (EH) alkyl side chains were examined in D-A copolymers composed of TPD and benzodithiophene (BDT) units. ${ }^{45}$ It was shown that alkyl chains on the TPD unit had a significant influence on the solubility and chain packing of the polymer, in addition to providing a 'fine-tuning' of molecular orbital levels. X-ray scattering revealed that the $\pi-\pi$ stacking distance is around $3.67 \AA$ in PCPDTTPD (see molecular structure in Fig. 6) polymers having linear side-chains ( $\mathrm{Bu}, \mathrm{He}$ and Oc), whilst for the $\mathrm{EH}$ branched copolymers, the $\pi-\pi$ stacks were separated by $3.86 \AA$ (Table 1), indicating a lower packing density. Copolymers PCPDTTPD-Oc and PCPDTTPD$\mathrm{EH}$ with Oc or EH groups had lower HOMO and LUMO energy levels, resulting in a relatively higher $V_{\mathrm{oc}}$ in OPV devices when blended with $\mathrm{PC}_{71} \mathrm{BM}$, permitting PCEs of up to $6.4 \%$ to be obtained in devices based on a PCPDTTPD-Oc:PC ${ }_{71} \mathrm{BM}$ blend. ${ }^{45}$ These findings are in qualitative agreement with a similar study on the furan-containing copolymer PDPP2FT (see molecular structure in Fig. 6), where it was found that linear branched chains permitted the formation of larger and closer packed nanoscale crystallites, compared to those formed from an almost identical polymer that instead

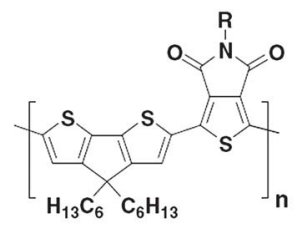

PCPDTTPD-Bu: $R=$ butyl PCPDTTPD-He: $R=$ hexyl PCPDTTPD-Oc: $\mathrm{R}=$ Octyl PCPDTTPD-EH: R=2-ethylhexyl

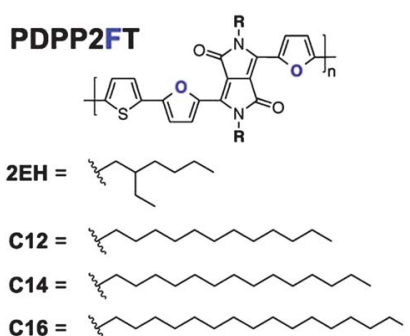

Fig. 6 The chemical structure of PCPDTTPD and PDPP2FT with various side chains. incorporated branched $\mathrm{EH}$ chains (Table 2). ${ }^{46}$ It is known that the degree of electronic coupling between adjacent polymer chains decays exponentially with $\pi-\pi$ stacking distance and can vary by as much as a factor of 4 as this distance is increased from 3.4 to $4.0 \AA{ }^{46}$ Thus branched side groups may introduce steric hindrance if polymer chains undergo packing, whereas linear side groups may result in a relatively coplanar backbone structure thereby allowing for closer $\pi-\pi$ stacking distances and consequently enhanced charge mobility. By understanding and utilizing such effects, it is possible to obtain substantial increases in OPV PCE.

Interestingly however, a contrasting effect was found in PBDTTPD-based OPV devices. ${ }^{47}$ Here GIXS was used to study the copolymer PBDTTPD having either two branched EH sidechains $(2 \mathrm{EH}, \mathrm{C} 8)$ or linear side-chains (C8, C14) on a BDT moiety. From the scattering patterns shown in Fig. 7 , it can be seen that the copolymer PBDTTPD having the branched sidechains adopts a preferential "face-on" $\pi-\pi$ stacking orientation whilst the equivalent polymer with linear side-chains does not show any preferential $\pi-\pi$ stacking orientation when processed under identical conditions. This apparent selectivity results in a dramatic improvement in device PCE from $4.1 \%$ to $7.5 \%$ when linear side-chains were replaced with branched side-chains.

Within the PTB series of copolymers synthesized with either thienothiophene (TT) or benzodithiophene (BDT) moieties, a

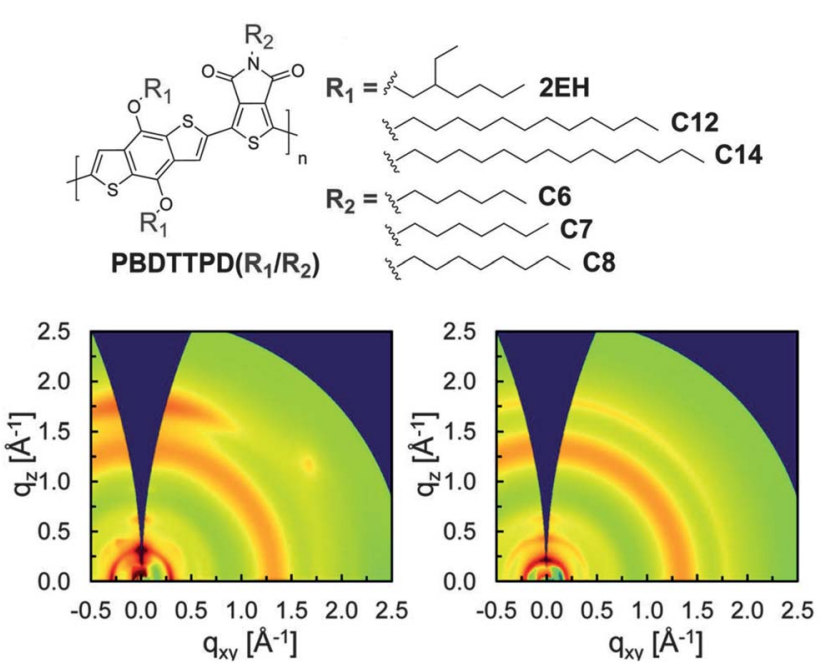

Fig. 7 Top: chemical structure of PBDTTPD with different side-chains on the BDT or TPD units. Bottom: 2D GIXS patterns of (left) PBDTTPD (2EH/C8) and (right) PBDTTPD (C14/C8) in optimized $\mathrm{BHJ}$ with $\mathrm{PC}_{71} \mathrm{BM}$. Figure reprinted from ref. 47, Copyright @ 2013, American Chemical Society.

Table 1 HOMO and LUMO levels, bandgap and photovoltaic performance of OPVs of PCPDTTPDs:PC 71 BM

\begin{tabular}{|c|c|c|c|c|c|c|c|c|}
\hline Polymer & HOMO $(\mathrm{eV})$ & LUMO $(\mathrm{eV})$ & $\begin{array}{l}\pi-\pi \\
\text { stacking distance }(\AA)\end{array}$ & $E_{\mathrm{g}}^{\mathrm{opt}}(\mathrm{eV})$ & $V_{\mathrm{oc}}(\mathrm{V})$ & $\begin{array}{l}J_{\mathrm{sc}}(\mathrm{mA} \\
\left.\mathrm{cm}^{-2}\right)\end{array}$ & $\mathrm{FF}(\%)$ & PCE (\%) \\
\hline PCPDTTPD-Bu & -5.08 & -3.43 & 3.67 & 1.57 & 0.70 & 9.22 & 35.7 & 2.3 \\
\hline PCPDTTPD-He & -5.12 & -3.47 & 3.67 & 1.59 & 0.75 & 13.2 & 57.4 & 5.7 \\
\hline PCPDTTPD-Oc & -5.29 & -3.63 & 3.67 & 1.59 & 0.75 & 14.1 & 60.7 & 6.41 \\
\hline PCPDTTPD-EH & -5.24 & -3.55 & 3.86 & 1.61 & 0.84 & 12.7 & 53.5 & 5.71 \\
\hline
\end{tabular}


Table 2 GIXS peak parameters for PDPP2FT derivatives and PCEs of OPV devices

\begin{tabular}{|c|c|c|c|c|c|}
\hline Polymers & $\begin{array}{l}\pi-\pi \text { stacking } \\
\text { distance }(\AA)\end{array}$ & $\begin{array}{l}\pi-\pi \\
\text { stacking } \\
\text { correlation } \\
\text { length }(\mathrm{nm})\end{array}$ & $\begin{array}{l}L \\
(\AA)\end{array}$ & $\begin{array}{l}\text { Lamellar } \\
\text { correlation } \\
\text { length (nm) }\end{array}$ & $\begin{array}{l}\text { Avg. } \\
\text { PCE (\%) }\end{array}$ \\
\hline PDPP2FT-C12 & 3.6 & 3.3 & 21 & 3.4 & 4.8 \\
\hline PDPP2FT-C14 & 3.6 & 3.6 & 23 & 3.6 & 6.2 \\
\hline PDPP2FT-C16 & 3.6 & 3.0 & 25 & 4.1 & 5.7 \\
\hline PDPP2FT-2EH & 3.7 & 1.1 & 13 & 2.7 & 5.0 \\
\hline
\end{tabular}

range of PCEs have been determined ranging from 2 to $8 \%$ dependent on the nature of the side-chain. ${ }^{48}$ It was shown using GIWAXS that branched side-chains attached to the BDT unit increased the $\pi-\pi$ stacking distance in the solid film and reduced the performance of the OPV device. ${ }^{48}$ However, the addition of branched side-chains to the TT unit did not have a significant impact on the $\pi-\pi$ stacking distance. Here, the performance of devices incorporating copolymers containing TT unit with branched alkyl side-chains was substantially higher, with such differences tentatively ascribed to favorable interactions with the PCBM component of the blend. An empirical correlation between $\pi-\pi$ stacking distance and the fill factor of PTB copolymer-based OPV devices was also demonstrated, with a reduced $\pi-\pi$ stacking distance in the polymer phase correlated with a larger FF in OPV devices.

The length of the alkyl side-chains was not found to significantly influence the absorption spectrum or molecular orbital levels in D-A copolymer PBDTTBTs. ${ }^{49}$ Nevertheless, the nanoscale morphology of polymer:PCBM blend thin-films can be dramatically altered. Transmission Electron Microscopy (TEM) images shown in Fig. 8 reveal that increasing the length of the alkyl side-chains can directly modify the morphology of the blend. ${ }^{49}$ Specifically, it was found that shorter side chains gave rise to a $\mathrm{BHJ}$ morphology, containing fullerene aggregates described by the authors as being 'pea-like', whereas blends of a fullerene and polymer having longer side chains formed a relatively coarse interpenetrating network characterized by larger phase separation between the components. Despite such variations in $\mathrm{BHJ}$ nanostructure, $\mathrm{X}$-ray scattering measurements did not indicate any differences in the polymer $\pi-\pi$ stacking distance. The changes in blend morphology were consequently attributed to variations in miscibility between the different polymers and PCBM.
The addition of conjugated side-chains to the backbone structure of D-A copolymers has also been explored, resulting in a two-dimensional (2D) conjugated system. Huo et al. reported a study of the 2D D-A copolymers PBDTTBT, PBDTTTZ created by attaching conjugated thienyl or 2-alkylthiophene side-chains to the electron-donating BDT units. ${ }^{50,51}$ Such materials were blended with $\mathrm{PC}_{71} \mathrm{BM}$ and used as the active layer in an OPV having a PCE in excess of $5 \% .^{50,51}$ A 2D BDT-based D-A copolymer named PBDTDTNT has also been shown to achieve a PCE of $6 \%$ when fabricated into an OPV.52 In D-A copolymers based on BDT and TT units (see chemical structures shown in Fig. 9), the 2D DA copolymers PBDTTT-E-T, PBDTTT-C-T and PBDTTT-S-T having conjugated side-chains exhibited better thermal stability, redshifted absorption, lower HOMO and LUMO energy levels, significantly higher hole mobility and greatly improved photovoltaic properties in comparison to their corresponding alkoxysubstituted analogues (i.e. having insulating side groups) PBDTTT-E, PBDTTT-C and PBDTTT-S. ${ }^{53,54}$ We summarize device and material properties taken from ref. 53 and 54 in Table 3.

The positions at which solubilising side-chains are attached to the repeat units of a copolymer has also been found to influence its physical and optoelectronic properties and consequently device performance. ${ }^{55,56}$ If significant steric hindrance is introduced by the side-chains, the maximum molecular weight of the copolymer that can be achieved through polymerization is however significantly reduced. ${ }^{57}$ The inappropriate positioning of side-chains can also result in twists along the conjugated backbone with such effects leading to a reduction in effective conjugation length and charge carrier mobility. ${ }^{58}$ For example in some D-A copolymers, it was found that side-chains attached at the 4-position of a thiophene ring result in less steric hindrance and consequently form more planar molecular structures. ${ }^{\mathbf{5 9 , 6 0}}$ In another study on two phenazine-based D-A copolymers, (see chemical structures shown in Fig. 10) it was found that film morphology and photovoltaic performances were dependent on the position of alkoxy chains on the phenazine unit, although the optical absorption and energy levels were not apparently affected by side-chain position. ${ }^{61}$ From the AFM and TEM morphologies shown in Fig. 10 it can be seen that large, coarse aggregates are formed in $\mathrm{P} 1 / \mathrm{PC}_{71} \mathrm{BM}$ blend film (with OPV devices having a PCE of $1.5 \%$ ), whereas a $\mathrm{P} 2 / \mathrm{PC}_{71} \mathrm{BM}$ blend formed a homogeneous and smooth film, producing devices having a PCE of $2.54 \% .^{61}$

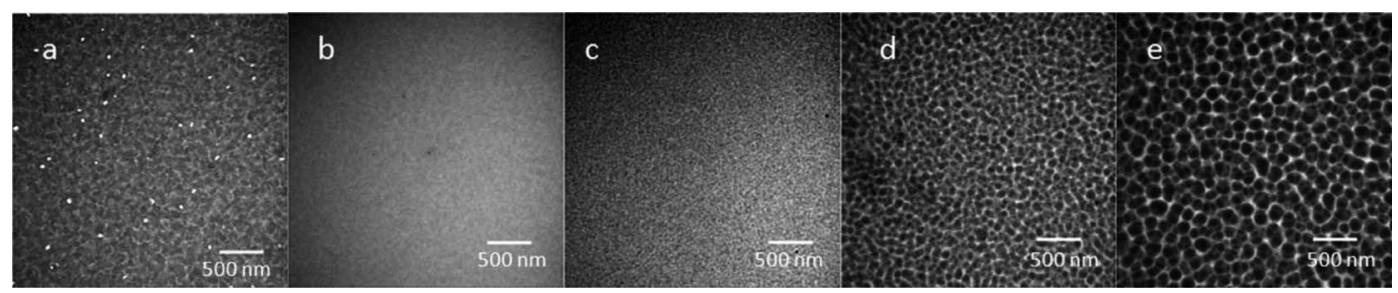

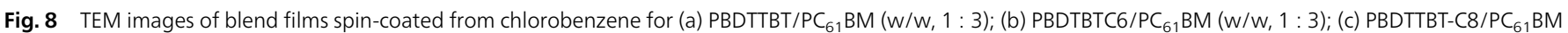

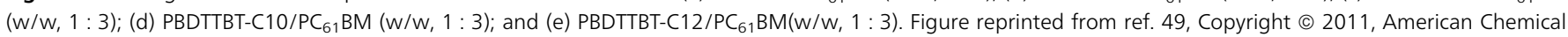
Society. 

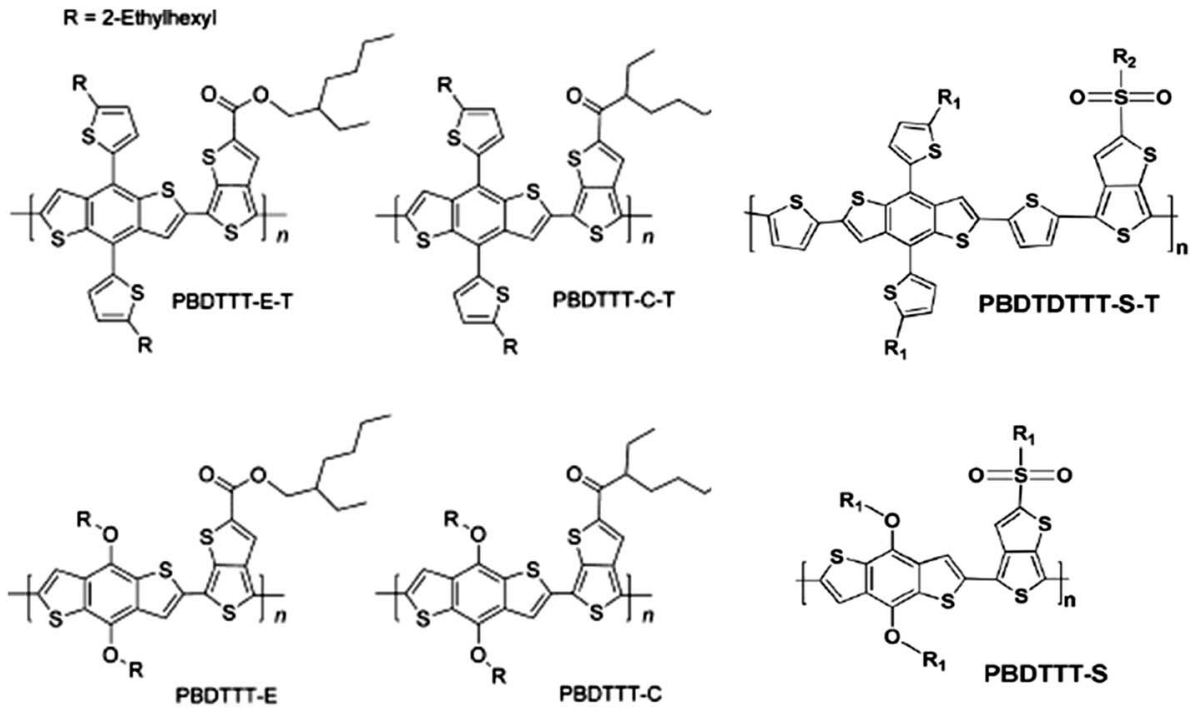

Fig. 9 Chemical structures of PBDTTT-E, PBDTTT-C, PBDTTT-S and their 2D D-A copolymer analogues PBDTTT-E-T, PBDTTT-C-T, PBDTTT-S-T.

Table 3 HOMO and LUMO levels, band-gap, SCLC mobility of PBDTTTs and the optimized photovoltaic performance of OPV devices

\begin{tabular}{|c|c|c|c|c|c|c|c|c|}
\hline Polymer & HOMO $(\mathrm{eV})$ & LUMO (eV) & $E_{\mathrm{g}}^{\mathrm{opt}}(\mathrm{eV})$ & $\begin{array}{l}\text { SCLC mobility } \\
\left(\mathrm{cm}^{-2} \mathrm{~V}^{-1} \mathrm{~s}^{-1}\right)\end{array}$ & $V_{\mathrm{oc}}(\mathrm{V})$ & $\begin{array}{l}J_{\mathrm{sc}}(\mathrm{mA} \\
\left.\mathrm{cm}^{-2}\right)\end{array}$ & $\mathrm{FF}(\%)$ & PCE (\%) \\
\hline PBDTTT-E & -5.04 & -3.19 & 1.63 & $1.50 \times 10^{-3}$ & 0.66 & 11.53 & 54.7 & 4.16 \\
\hline PBDTTT-C & -5.07 & -3.21 & 1.60 & $5.53 \times 10^{-4}$ & 0.70 & 15.51 & 59.2 & 6.43 \\
\hline PBDTTT-C-T & -5.11 & -3.25 & 1.58 & $2.7 \times 10^{-1}$ & 0.74 & 17.48 & 58.7 & 7.59 \\
\hline PBDTTT-S & -5.10 & -3.51 & 1.65 & $4.56 \times 10^{-4}$ & 0.76 & 13.85 & 58.0 & 6.11 \\
\hline
\end{tabular}

\subsection{Effects of bridging units}

The bridging units that exist between the donor and acceptor moieties of $\mathrm{D}$-A copolymers have been found to affect the light absorption, energetic band-gap and charge-carrier mobility of the copolymer and thus consequently affect OPV device power conversion efficiency. Bridging units can also affect material solubility. For example the replacement of thiophene with furan heterocycles along the backbone of D-A copolymers enables the use of relative short side chains owing to the improved
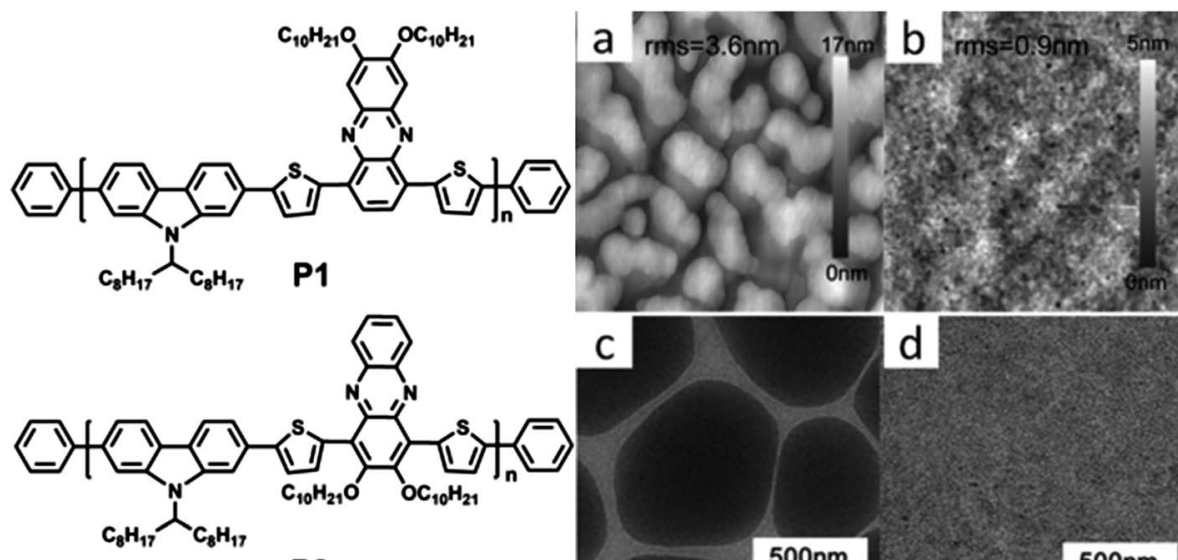

P2

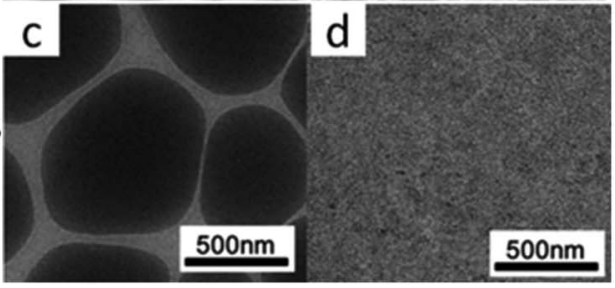

Fig. 10 Left: chemical structures of two phenazine-based D-A copolymers. Right: (a) AFM and (c) TEM images of P1/PC 71 BM (1:3, w/w), and (b) AFM and (d) TEM images of $\mathrm{P} 2 / \mathrm{PC}_{71} \mathrm{BM}(1: 3, \mathrm{w} / \mathrm{w})$ blend films. AFM images are $2 \mu \mathrm{m} \times 2 \mu \mathrm{m}$. The scale bar in TEM images is $500 \mathrm{~nm}$. Figure reprinted from ref. 61 , Copyright $\odot 2013$ Wiley Periodicals, Inc. 
solubility of furan in common organic solvents. ${ }^{62}$ In other studies, the length of the $\pi$-conjugated bridge between $\mathrm{D}$ and $\mathrm{A}$ groups was found to affect the electronic and photovoltaic properties of copolymers based on carbazole and quinoxalinoporphyrin. ${ }^{63}$ By increasing the length of the $\pi$-conjugated bridge from thiophene to bithiophene and then to terthiophene, the hole mobility of the copolymers increased gradually and the optical absorption spectra broadened..$^{63}$ These effects were correlated with an improved PCE in a solar cell device utilizing these semiconductors. In other work on copolymers based on a BDT (benzodithiophene) donor unit and a BT (benzothiadiazole) acceptor unit, the choice of $\pi$-bridging unit was found to significantly affect both the molecular architecture and the optoelectronic properties of the polymer. ${ }^{64}$ A series of representative polymers is shown in Fig. 11. It was found that when the $\pi$-bridge was varied from furan to thiophene, and then to thienothiophene, the absorption spectrum of the polymer underwent a relative red-shift. Furthermore, the conformation of the copolymer repeat unit (as inferred from Density Functional Theory (DFT) calculations) changed from a 'zig-zag' arrangement to one in which the repeat unit was relatively linear. ${ }^{64}$ Such structural and optoelectronic changes were correlated with improved charge carrier mobility and OPV device performance (Table 4). It was concluded therefore that a thienothiophene bridge conferred significant advantages in this class of OPV-applicable D-A copolymer.

Selenium atoms are more electron-rich than sulfur atoms and aromatic rings containing selenium have electrons that are consequently more delocalised compared to their thiophene counterparts. ${ }^{65-67} \mathrm{D}-\mathrm{A}$ copolymers bridged by selenophene units have been found to exhibit red-shifted absorption spectra and lower optical band-gaps compared to identical copolymers bridged by thiophene units. ${ }^{65-67}$ Several selenophene containing polymers have also demonstrated enhanced charge-carrier mobility compared with thiophene-based polymers. ${ }^{68-71}$ For example, a PCE of $7.2 \%$ was obtained in single-junction OPV devices based on selenophene-bridged PBDTTSeDPP, compared with the furan-bridged polymer PBDTT-FDPP and thiophenebridged PBDTT-DPP (PCEs of 4.7 and 6.5 respectively). ${ }^{72}$ In contrast however, reduced field-effect charge mobility and reduced PCE have been found in selenophene-bridged copolymers comprising 2,7-linked carbazole or fluorene donor moieties and benzothiadiazole units with or without alkoxy substituents as acceptor moieties (see chemical structures in Fig. 12). ${ }^{73}$ Device studies indicate that relative to thiophenecontaining copolymers, selenophene-bridged copolymers are characterized by OPVs having higher $J_{\mathrm{sc}}$ but smaller $V_{\mathrm{oc}}$ and $\mathrm{FF},{ }^{66,73}$ or exhibit both a reduced $J_{\mathrm{sc}}$ and $\mathrm{FF}^{73}$ In this series of copolymers, the reduced efficiency of OPVs containing selenium substituted materials was attributed to lower charge carrier mobility and reduced molar extinction coefficient that limited the ability of the copolymer to harvest light and transport charge efficiently though the device. ${ }^{73}$

The bridging atoms in the donor or acceptor moieties of the copolymers have also been shown to significantly influence the nanostructure of polymer and polymer:fullerene blend thinfilms. ${ }^{7,75}$ For example, the carbon-bridged dithiophene-based copolymer PCPDTBT (see Fig. 13) is typically amorphous when cast into a solid film. In contrast its silicon-bridged analog PSBTBT is semi-crystalline ${ }^{76,77}$ with GIWAXS demonstrating a preferential 'edge-on' orientation of molecular chains, with the $\pi-\pi$ stacking plane parallel to the substrate. ${ }^{76}$ It was suggested that the longer $\mathrm{C}-\mathrm{Si}$ bond in PSBTBT permitted better interchain molecular packing due to reduced steric hindrance between the alkyl side-group and the thiophene rings. As PSBTBT is a semi-crystalline polymer, its hole-carrier mobility (as determined by field effect transistor measurements) is approximately 3 times higher than that of the relatively amorphous polymer PCPDTBT. ${ }^{78}$ Nevertheless, an optimized device PCE of around 5.5\% was achieved in OPVs made from both
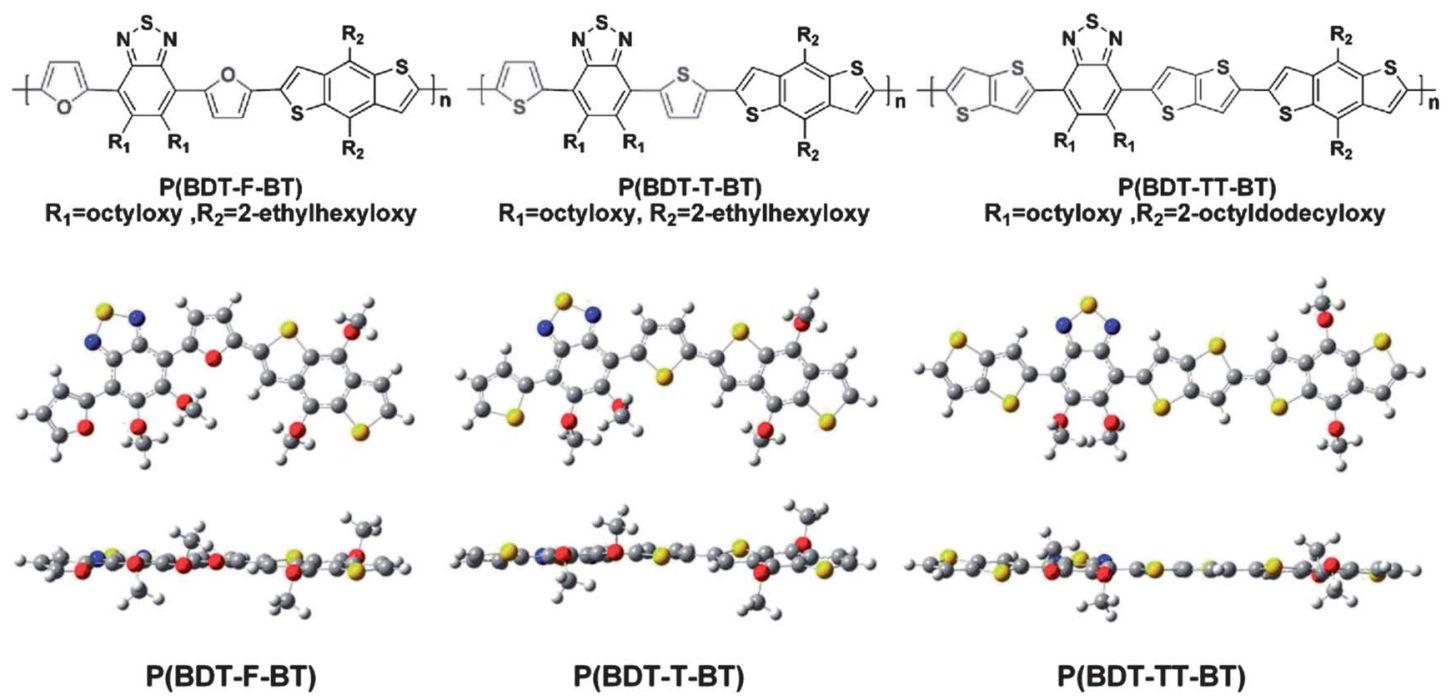

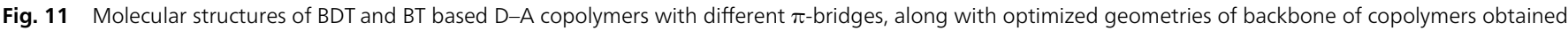

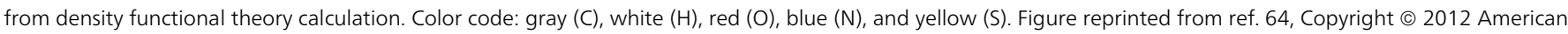
Chemical Society. 
Table 4 Photovoltaic properties of devices made from P(BDT-F-BT), P(BDT-T-BT) and P(BDT-TT-BT) and PC ${ }_{71} B M$

\begin{tabular}{|c|c|c|c|c|c|c|}
\hline Polymer & Blend ratio & $V_{\mathrm{oc}}(\mathrm{V})$ & $\begin{array}{c}J_{\mathrm{sc}}(\mathrm{mA} \\
\left.\mathrm{cm}^{-2}\right)\end{array}$ & FF (\%) & PCE (\%) & SCLC mobility $\left(\mathrm{cm}^{-2} \mathrm{~V}^{-1} \mathrm{~s}^{-1}\right)$ \\
\hline P(BDT-F-BT) & $1: 2$ & 0.94 & 6.50 & 46 & 2.81 & $2.1 \times 10^{-3}$ \\
\hline P(BDT-T-BT) & $1: 1.5$ & 0.82 & 9.45 & 48 & 3.72 & $2.9 \times 10^{-3}$ \\
\hline $\mathrm{P}(\mathrm{BDT}-\mathrm{TT}-\mathrm{BT})$ & $1: 1.5$ & 0.69 & 11.34 & 63 & 4.93 & $8.6 \times 10^{-3}$ \\
\hline
\end{tabular}<smiles>CC(C)(C)c1ccc2c(c1)-c1cc(-c3ccc(-c4ccc(-c5ccc(C(F)(F)F)s5)c5nsnc45)s3)ccc1-2</smiles>

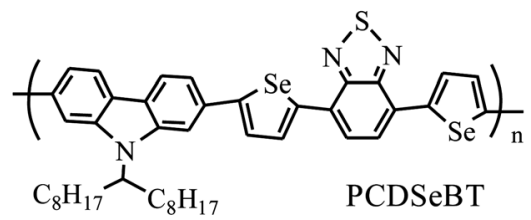<smiles>CCCCC1(CCCC)c2cc(-c3ccc(-c4ccc(-c5ccc(C(C)(C)C)s5)c5nsnc45)s3)ccc2-c2ccc(C(C)(C)C)cc21</smiles>

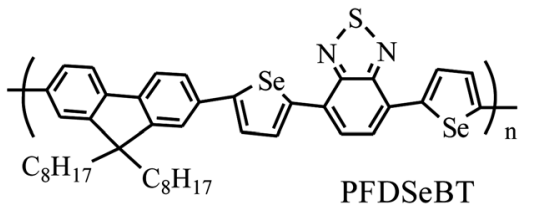

Fig. 12 Chemical structures of thiophene- and selenophene-bridged D-A copolymers PCDTBT, PCDSeBT, PFDTBT and PFDSeBT.

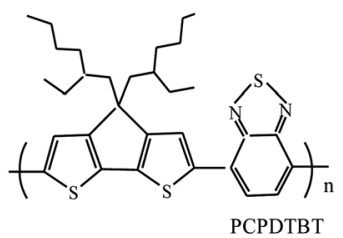

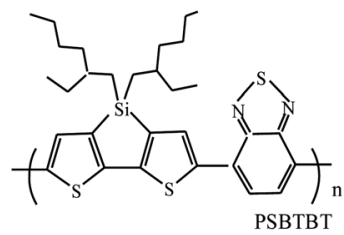

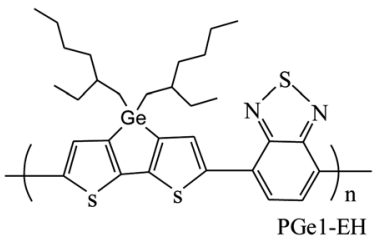

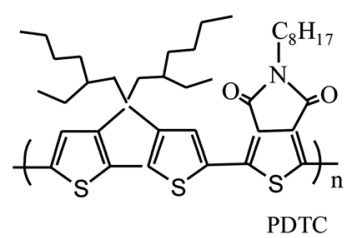

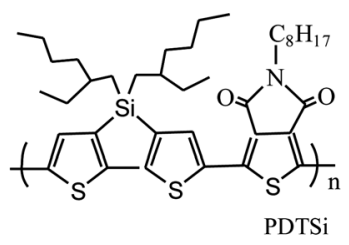

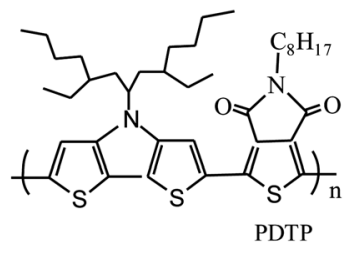

Fig. 13 Chemical structures of PCPDTBT, PSBTBT, PGe1-EH, PDTC, PDTSi and PDTP.

PCPDTBT or PSBTBT copolymers, although it is important to acknowledge that optimization was achieved via the use of solvent additives ${ }^{79}$ and post-deposition thermal annealing ${ }^{76,78}$ respectively. These different optimization protocols highlight the complexity in OPV research by demonstrating that polymers with apparently unfavourable OPV characteristics (for example, an amorphous nature and relatively low charge mobility) can still be used to create devices with relatively high PCEs.
In the germanium-bridged derivative of PCPDTBT - named PGe1-EH (see Fig. 13), it was found that OPV devices had a low PCE of $2.9 \%{ }^{80}$ It is clear that a $\mathrm{C}-\mathrm{Ge}$ bond is longer than that of a $\mathrm{C}-\mathrm{Si}$ bond, however the impact of this difference on molecular packing in PGe1-EH and its relationship with the photovoltaic performance has not yet been determined. In other work, it was found that the Ge-bridged copolymer with methyl side groups (MeGeBT) had a higher hole-carrier mobility and improved miscibility with

Table 5 HOMO and LUMO levels, bandgap and photovoltaic performance of OPVs made from PDTC, PDTSi and PDTP

\begin{tabular}{|c|c|c|c|c|c|c|c|c|}
\hline polymer & HOMO $(\mathrm{eV})$ & LUMO (eV) & $E_{\mathrm{g}}(\mathrm{eV})$ & $E_{\mathrm{g}}^{\mathrm{opt}}(\mathrm{eV})$ & $V_{\mathrm{oc}}(\mathrm{V})$ & $J_{\mathrm{sc}}\left(\mathrm{mA} \mathrm{cm}^{-2}\right)$ & FF (\%) & PCE (\%) \\
\hline PDTC & -5.43 & -3.25 & 2.18 & 1.67 & 0.80 & 10.04 & 47 & 3.7 \\
\hline PDTSi & -5.44 & -3.17 & 2.27 & 1.70 & 0.91 & 2.32 & 56 & 1.18 \\
\hline PDTP & -5.16 & -3.08 & 2.08 & 1.59 & 0.71 & 2.53 & 50 & 0.91 \\
\hline
\end{tabular}



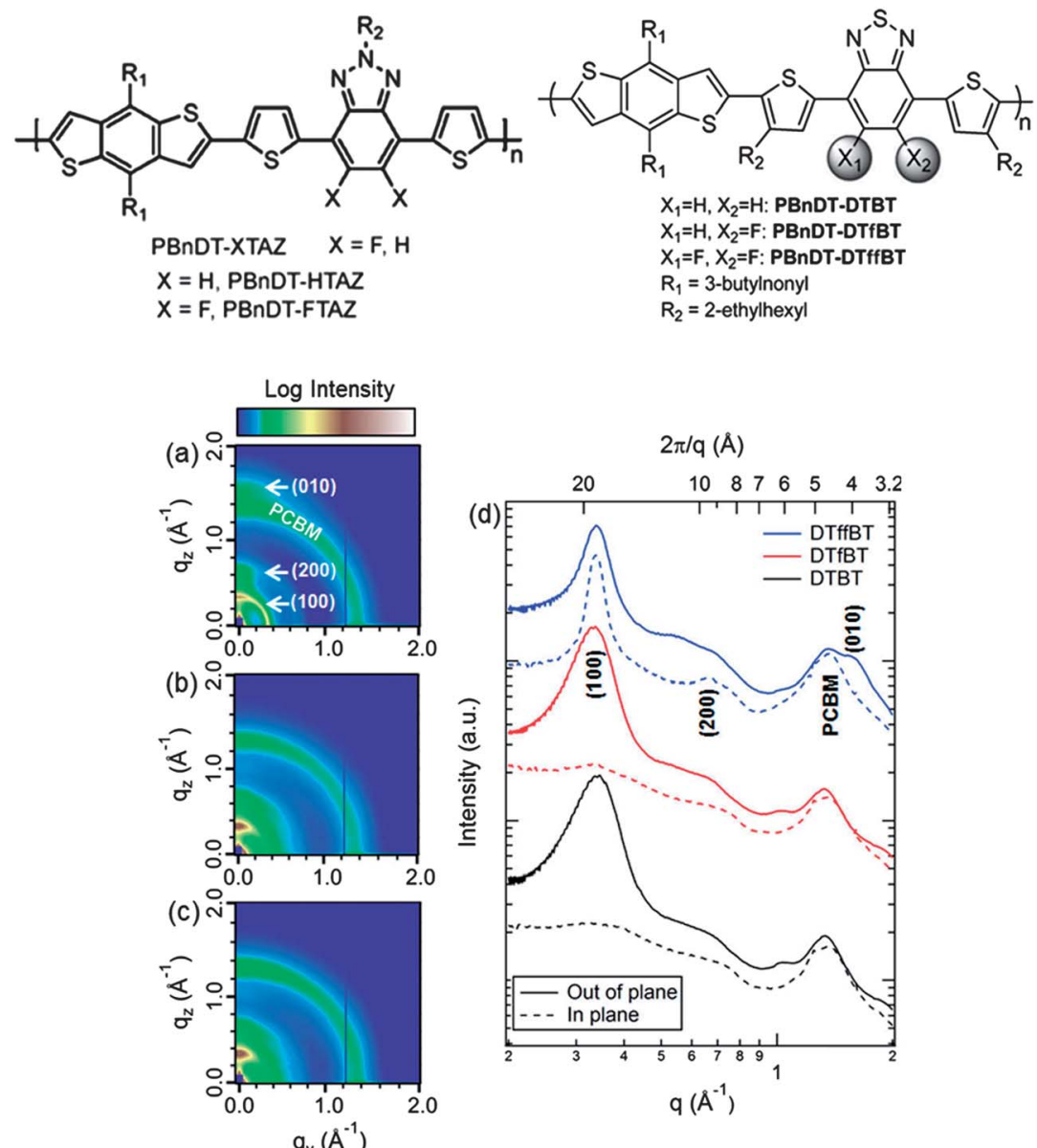

Fig. 14 Top: chemical structures of PBnDT-HTAZ, PBnDT-FTAZ, PBnDT-DTBT, PBnDT-DTfBT, and PBnDT-DTffBT. Bottom: 2D GIWAXS images of blend films based on (a) PBnDT-DTffBT, (b) PBnDT-DTfBT, and (c) PBnDT-DTBT. (d) In-plane and out-of-plane $20^{\circ}$ sectors with the polymer peaks labeled along with the typical scattering contribution from PC $_{61}$ BM. Figure reprinted from ref. 96, Copyright $\odot$ 2013, American Chemical Society.

$\mathrm{PC}_{71} \mathrm{BM}$; properties that lead to the realization of OPVs having a higher PCE compared to devices fabricated using the Si-bridged copolymer MeSiBT. ${ }^{81}$ Other OPV device studies using copolymers containing electron-deficient thienopyrroledione (TPD) and electron-rich dithiophene units bridged by carbon, silicon and nitrogen atoms (namely PDTC, PDTSi and PDTP, respectively - see Fig. 13) demonstrated a reduction in PCE when the dithiophene units were Si- and N-bridged (Table 5) ${ }^{82}$ Although the PCE of OPVs fabricated using PDTSi and PDTP can be improved slightly by casting from different solvents, the resultant PCEs are still lower than that of devices made from PDTC. It was concluded therefore that the use of Si- and N-bridges did not present an effective strategy to increase OPV efficiency using this class of D-A copolymers. Finally, $\mathrm{Wu}$ et al. developed an $\mathrm{sp}^{2}-\mathrm{sp}^{2}$ ethylene $(\mathrm{C}=\mathrm{C})$ bridged dithienocarbazole-based D-A copolymer called PDTBCDTBT. The PCE of OPVs based on this copolymer reached $6.2 \%$; an efficiency amongst the highest of those obtained from C-, Si- and N-bridged analogous copolymers. ${ }^{83}$

\subsection{Effects of fluorine substitution}

Substitution of carbon or hydrogen atoms with fluorine in either the donor or acceptor unit of a D-A copolymer has been shown to modify the molecular orbital levels of a copolymer, and subsequently impact upon the photovoltaic performance of an OPV device. $^{84-87}$ Fluorination of D-A copolymers can simultaneously lower the HOMO and LUMO energy levels, causing only minor changes to the optical band-gap..$^{88,89}$ Consequently, reduced energy-loss on electron transfer from the polymer donor to fullerene acceptor (via reduction of the LUMO level) and enhanced stability against photo-oxidation (by lowering the HOMO level) can be achieved, with such changes predicted to increase the efficiency and operational lifetime of organic electronic devices. ${ }^{90}$ Furthermore, $\mathrm{C}-\mathrm{F} \cdots \mathrm{H}, \mathrm{F} \cdots \mathrm{F}$ and $\mathrm{C}-\mathrm{F} \cdots \pi_{\mathrm{F}}$ atomic interactions can also improve molecular organization resulting in shorter $\pi-\pi$ stacking distances that enhance charge carrier mobility. ${ }^{91}$ Fluorination is therefore a promising approach to improving the PCE of OPV devices by increasing the $V_{\mathrm{oc}}, J_{\mathrm{sc}}$ and FF either monotonically ${ }^{92,93}$ or simultaneously. ${ }^{89,94}$ For example, in OPV devices utilizing the fluorinated copolymer F-PCPDTBT (otherwise equivalent to PCPDTBT as shown in Fig. 13, with the exception of a fluorine atom attached on the BT unit), power conversion efficiencies of up to $6 \%$ were achieved; a value greater than the $3.6 \%$ determined from non-fluorinated PCPDTBT-based solar cells that were processed under identical conditions. ${ }^{95}$ 
Indeed, time-delayed charge extraction measurements determined a relatively low yield of both geminate and non-geminate charge recombination in solar cell devices using F-PCPDTBT in comparison with the non-fluorinated PCPDTBT. ${ }^{95}$

In other work, You et al. introduced two fluorine atoms to the benzotriazole and benzothiadiazol unit, and synthesized the fluorinated D-A copolymers PBnDT-FTAZ ${ }^{89}$ and PBnDTDTffBT $^{94}$ whose chemical structures are shown in Fig. 14. Both of these materials (when blended with $\mathrm{PC}_{61} \mathrm{BM}$ ) were used to create OPV devices having a relatively high PCE of over $7 \%$. Due to the high hole mobility of PBnDT-FTAZ, it was shown that a relatively-high PCE of $6 \%$ could be realized for PBnDTFTAZ:PC ${ }_{61} \mathrm{BM}$ OPV devices in which the active layer thickness exceeded $1 \mu \mathrm{m}$. A follow-on study ${ }^{96}$ on the impact of the number of fluorine atom substitutions per monomer group $(0,1$ or 2 , as shown in the chemical structures in Fig. 14) attributed the relatively larger $V_{\text {oc }}$ obtained in OPV devices based on such materials to a lowering of the HOMO level of the fluorinated copolymer (see a summary of HOMO levels in Table 6), with improvements in $J_{\mathrm{sc}}$ and $\mathrm{FF}$ tentatively ascribed to reduced charge recombination within the photoactive layer. Measurements on OPV devices under a range of light intensities also confirmed a reduced bimolecular recombination rate with increased fluorine concentration. ${ }^{96}$ GIWAXS measurements of neat films of the doubly fluorinated copolymer PBnDT-DTffBT revealed an increase in X-ray scattering intensity compared to its single and non-fluorinated analogues from both the in-plane lamellar packing and out-of-plane $\pi-\pi$ stacking. These results were consistent with miscibility measurements of the fluorinated polymers and $\mathrm{PC}_{61} \mathrm{BM}$ using resonant soft $\mathrm{X}$-ray

Table $6 \mathrm{HOMO}$ and LUMO levels, band-gap, SCLC mobility of PBnDT-HTAZ and PBnDT-FTAZ, and optimized photovoltaic performance

\begin{tabular}{|c|c|c|c|c|c|c|c|c|}
\hline Polymer & HOMO (eV) & LUMO (eV) & $E_{\mathrm{g}}^{\mathrm{opt}}(\mathrm{eV})$ & $\begin{array}{l}\text { SCLC mobility } \\
\left(\mathrm{cm}^{-2} \mathrm{~V}^{-1} \mathrm{~s}^{-1}\right)\end{array}$ & $V_{\mathrm{oc}}(\mathrm{V})$ & $J_{\mathrm{sc}}\left(\mathrm{mA} \mathrm{cm}^{-2}\right)$ & FF (\%) & PCE (\%) \\
\hline PBnDT-HTAZ & -5.29 & -2.87 & 1.98 & $3.34 \times 10^{-6}$ & 0.71 & 11.28 & 54.5 & 4.3 \\
\hline PBnDT-FTAZ & -5.36 & -3.05 & 2.00 & $6.76 \times 10^{-5}$ & 0.79 & 12.45 & 72.2 & 7.1 \\
\hline PBnDT-DTBT & -5.40 & -3.13 & 1.70 & $\mathrm{n} / \mathrm{a}$ & 0.87 & 10.03 & 57.3 & 5.0 \\
\hline PBnDT-DTffBT & -5.54 & -3.33 & 1.70 & $\mathrm{n} / \mathrm{a}$ & 0.91 & 12.91 & 61.2 & 7.2 \\
\hline
\end{tabular}
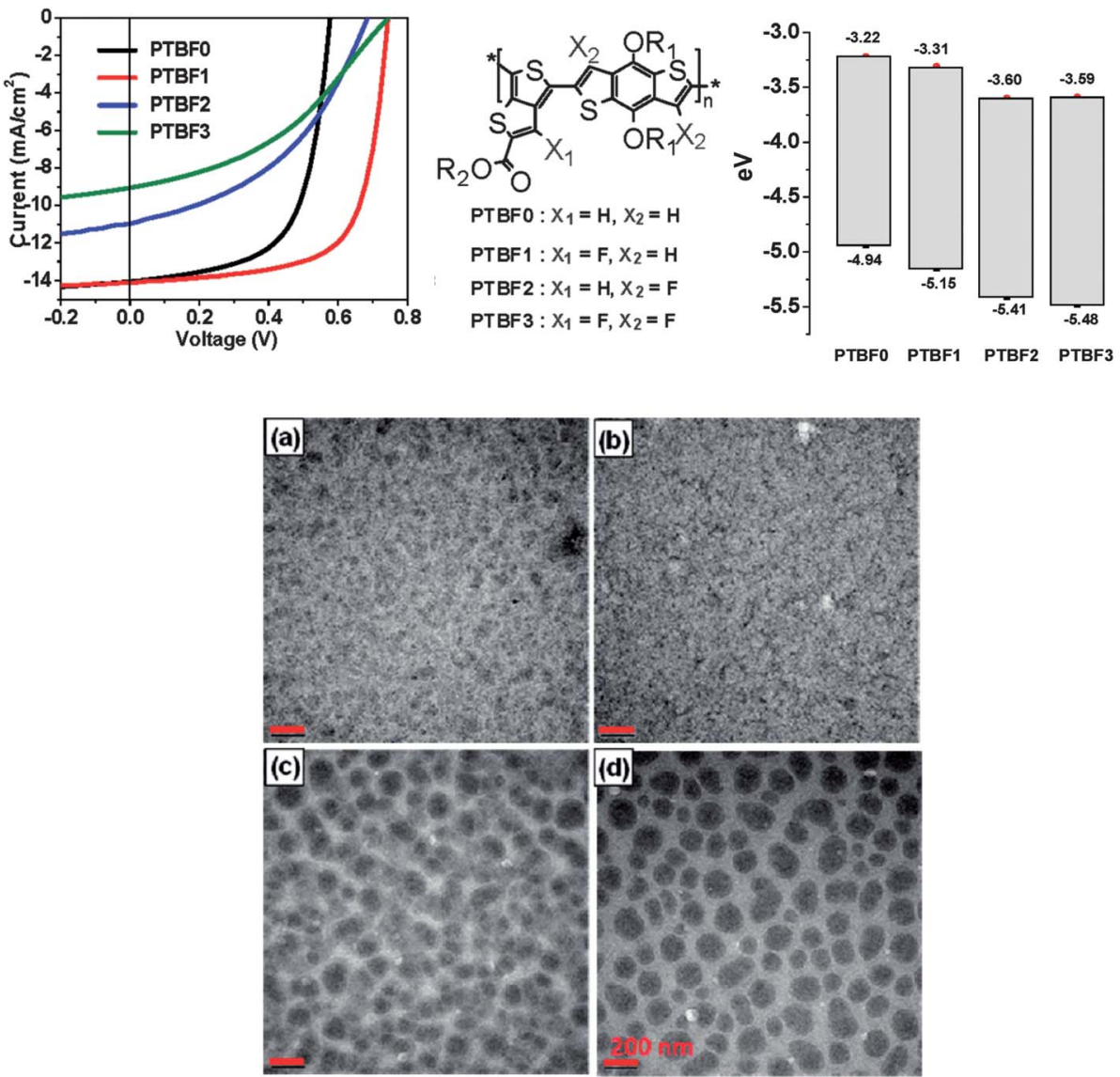

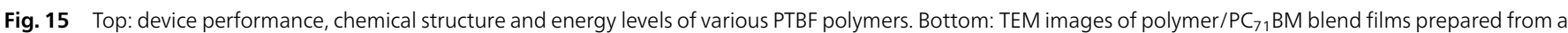
DCB solvent: PTBF0 (a), PTBF1 (b), PTBF2 (c), and PTBF3 (d). Scale bar = $200 \mathrm{~nm}$. Figure reprinted from ref. 97, Copyright @ 2011, American Chemical Society. 
scattering measurements (R-SoXS). ${ }^{96}$ Here, it was shown that the miscibility of $\mathrm{PC}_{61} \mathrm{BM}$ with the non-fluorinated polymer PBnDT-DTBT was greater than in the fluorinated analogue PBnDT-DTfBT (being $21 \%$ and $12 \%$ by weight respectively). This resulted in the formation of larger polymer and fullerene domains having relatively higher purity in the PBnDTDTffBT:PC ${ }_{61}$ BM blend.

Incorporation of fluorine into various positions on polythienothiophene-co-benzodithiophenes (PTBF) copolymers has been found to change device efficiency between $2.3 \%$ and $7.2 \% .^{97}$ In all cases, the energy band-gap of the copolymer was increased after fluorination. It was shown that PTBF copolymers containing mono-fluorinated thienothiophene units resulted in the best solar cell performance. ${ }^{97}$ Perfluorination of the polymer backbone led to poor compatibility with $\mathrm{PC}_{71} \mathrm{BM}$ and consequently reduced photovoltaic performance. As shown in Fig. 15, polymer:fullerene blends made from PTBF0 and PTBF1 and $\mathrm{PC}_{71} \mathrm{BM}$ were characterized by relatively fine features, which are typical for nanoscale phase separation. In contrast, larger $\mathrm{PC}_{71} \mathrm{BM}$ domains ranging in size from 50 to $200 \mathrm{~nm}$ were found to exist in blend thin-films of PTBF2 and PTBF3, suggesting relatively large-scale phase separation. ${ }^{97}$ This difference in morphology was attributed to the fluorophobicity of $\mathrm{PC}_{71} \mathrm{BM}$ molecules and the enhanced self-organization ability of perfluorinated polymer chains. The strong driving force for the development of relatively long-range order is partly driven by the planarity of the polymer backbone; a property that favors the exclusion of fullerene molecules and induces phase separation in the blends. Such physical properties however come at a price; it was shown that perfluorination of the polymer backbone resulted in poor stability against attack by singlet oxygen.

\section{The impact of fullerene size and side- group structure on molecular mixing and photovoltaic device performance}

The choice of electron-acceptor in OPV studies has often focused on the use of $\mathrm{PC}_{61} \mathrm{BM}$ or $\mathrm{PC}_{71} \mathrm{BM}$, with the latter exhibiting enhanced optical absorption at visible wavelengths.
Nevertheless, a number of other fullerene derivatives having additional or alternative side-groups compared to PCBM (see Fig. 16) have attracted attention as potential high-performance electron acceptors. ${ }^{{ }^{8-103}}$ Critically, such fullerene derivatives may not necessarily behave as 'universal' good electronacceptors in BHJ OPVs as variations in fullerene molecular structure affect not only electron affinity, but also the ability of the molecule to self-organize and mix with the electrondonating polymer.

In comparison to mono-PCBM, higher adduct versions of PCBM, namely bis-PCBM and tris-PCBM, exhibit LUMO levels closer to vacuum..$^{\mathbf{9 8}, 99}$ Ideally, such changes result in a reduction in energetic losses associated with electron transfer between polymer and fullerene and in principle provide an alternative approach to increase the $V_{\text {oc }}$ in a polymer:fullerene OPV. Indeed, it was found that device $V_{\text {oc }}$ increased by $0.15 \mathrm{~V}$ (from 0.58 to $0.73 \mathrm{~V}$ ) when the electron acceptor was changed from PCBM to bis-PCBM in a P3HT-based OPV. ${ }^{98}$ This increase resulted in an overall improvement in PCE as both the device $J_{\text {sc }}$ and FF were relatively unchanged upon fullerene substitution. Note however, that bis-PCBM needs additional purification in order to remove traces of alternative adducts that poorly define the LUMO level of the fullerene mixture or otherwise cause charge traps. ${ }^{98,99}$ It has been shown that tris-PCBM has a LUMO level closer to vacuum than either mono- or bis-PCBM and when used in an OPV device, and (using P3HT as the electron donor) a relatively high $V_{\text {oc }}$ can be obtained. ${ }^{104}$ However the $\mathrm{FF}$ and $J_{\mathrm{sc}}$ of such devices are significantly reduced, resulting in very low PCEs. Detailed studies of the photo-physics, charge transport properties and blend morphology have been used to provide key insight into such device results. ${ }^{\mathbf{1 0 4 , 1 0 5}}$ Although the yield of free charges (as probed using transient absorption spectroscopy) is comparable for all P3HT:fullerene blends, higher-adduct fullerenes have been found to have progressively reduced electron mobility compared to PCBM. This can be partly explained by the relatively amorphous nature of higher-adduct fullerenes that inhibit the ability of the molecules to aggregate and form percolated electron transporting networks when cast into a $\mathrm{BHJ}$ blend. Furthermore, differences in relative crystallinity of the

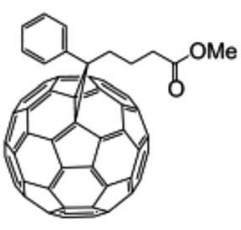

$\mathrm{PC}_{61} \mathrm{BM}$

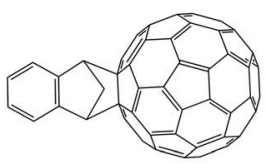

ICMA

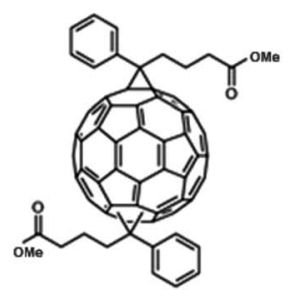

bisPCBM

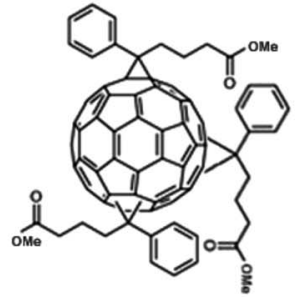

trisPCBM

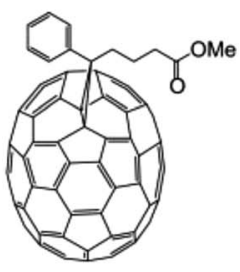

$\mathrm{PC}_{71} \mathrm{BM}$

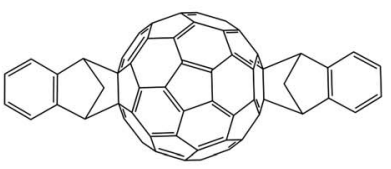

ICBA

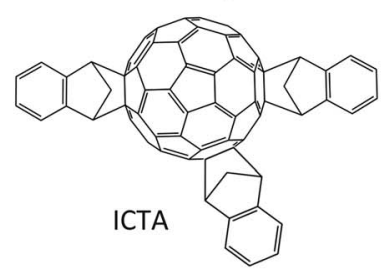

Fig. 16 Molecular structures of a few different types of fullerene derivative. 
multi-adduct fullerenes also affect both the nanostructure of the polymer phase of a blend film and the ability of the fullerene to dissolve in the amorphous polymer phase.

A promising alterative to PCBM is the fullerene derivative ICMA and its higher adducts ICBA and ICTA (having two and three side-groups respectively). ${ }^{\mathbf{1 0 0 , 1 0 6}}$ In qualitative agreement with studies on P3HT:bis-PCBM, P3HT:ICBA solar cells have a $V_{\text {oc }}$ of up to $0.84 \mathrm{~V}$ - an open-circuit voltage that is one of the highest obtained to date for $\mathrm{BHJ}$ OPV devices employing $\mathrm{P} 3 \mathrm{HT}$ as the electron donor. ${ }^{107}$ This resulted in a PCE of up to $6.5 \%$ in a P3HT:ICBA device, an observation demonstrating that a high $V_{\text {oc }}$ can be obtained without causing a significant reduction in $J_{\mathrm{sc}}$ or $\mathrm{FF} \cdot{ }^{107}$ ICBA has also been found to improve device PCE by $50 \%$ compared to PCBM when blended with the thiazolothiazole-dithienosilole based donor-acceptor copolymers PSEHTT, PSOTT and PSOxTT. ${ }^{108}$ The application of ICTA as electron acceptor in P3HT based OPV devices does not however produce efficient photovoltaic performance, with PCE values limited to $2.5 \%{ }^{106}$ Here, the reduced electron mobility of ICTA has been proposed as the dominant factor for low device performance, ${ }^{\mathbf{1 0 6}}$ with the presence of multiple side-groups increasing the separation between $\mathrm{C}_{60}$ moieties and consequently reducing the efficiency of electron transfer. ${ }^{109}$

Other studies on OPV devices using either Si-PCPDTBT or PFODTBT as electron donor and ICMA as electron acceptor have demonstrated a lower PCE compared to devices using PCBM as the electron acceptor. ${ }^{\mathbf{1 1 0}}$ Even lower PCEs have been determined in devices incorporating higher adduct derivatives of ICMA. This trend can be linked to a progressively smaller energetic offset between the LUMO levels of the copolymer and the fullerene. Work by Faist et al. ${ }^{110}$ has empirically determined a minimum energetic offset between LUMO levels in these blend systems below which photoluminescence quenching is reduced and charge transfer is effectively 'switched off'. Note that the photocurrent generation step precedes the transport of free charge carriers though the $\mathrm{BHJ}$ blend; a process that may also be inefficient owing to the relatively low electron mobility of ICBA and ICTA. Other work on OPV devices utilizing a blend of PSPDTTBT and ICBA have demonstrated higher PCEs compared to devices incorporating PCBM as the electron acceptor. ${ }^{111}$ Although PCBM has been shown to have a significantly higher field-effect electron mobility than ICBA when prepared in a pure film, the electron and hole mobility were found to be more balanced in an ICBA blend film (as determined in a space-charge limited conduction regime). This observation was correlated with the higher photovoltaic performance of a PSPDTTBT:ICBA blend. This result was further explained on the basis of contact angle measurements that characterized the surface energy $(\gamma)$ of PSPDTTBT, ICBA and PCBM. ${ }^{111}$ Here, the largest difference in surface energies $(\Delta \gamma)$ was determined between PSPDTTBT and ICBA; a property that is believed to provide the driving force to create a more phaseseparated mixture of polymer and fullerene, facilitating the formation of semi-crystalline polymer phases. Variations in $\Delta \gamma$ and the substrate surface energy also provide a driving force for vertical stratification in the blend; a process that may also result in the formation of a favourable $\mathrm{BHJ}$ morphology having improved OPV device efficiency. ${ }^{111}$
Morphological studies on $\mathrm{BHJ}$ blends comprising various polymers with indene $\mathrm{C}_{60}$ bis-adducts have provided additional insight into the necessary design rules that help predict whether a polymer:fullerene blend will perform well when fabricated into an OPV device. ${ }^{112-114}$ For example the polymer PBTTT is a relatively crystalline polymer having adjacent side-groups that are positioned sufficiently far apart such they can potentially permit the molecular intercalation of fullerene molecules. To explore this process, PBTTT:fullerene blends have been characterized using X-ray diffraction techniques to determine the extent of bimolecular packing through changes in the lamella spacing between adjacent PBTTT chains. It has been shown that the number of side-groups attached to the fullerene cage, together with the size of the fullerene cage $\left(\mathrm{C}_{60}\right.$ or $\left.\mathrm{C}_{70}\right)$ strongly influence the degree of bimolecular mixing.

For example, blends of PBTTT: $\mathrm{PC}_{71} \mathrm{BM}$ have been shown to exhibit bimolecular mixing whereas blends of PBTTT:bis- $\mathrm{PC}_{71} \mathrm{BM}$ do not. ${ }^{\mathbf{1 1 2}}$ This process is illustrated in Fig. 17 where thin-film Xray diffraction patterns of each blend are plotted together with the X-ray diffraction of pure PBTTT. Here, the peaks correspond to multiple-order X-ray diffraction from adjacent polymer chains packed along the lamella direction. It can be seen that blends of PBTTT: $\mathrm{PC}_{71} \mathrm{BM}$ are characterized by diffraction peaks that are shifted to lower $q$ values relative to that of pure PBTTT, indicating an increase in the separation distance between adjacent molecular backbones. In contrast, no change in the positions of the scattering features are observed in a PBTTT:bis-PC ${ }_{71} \mathrm{BM}$ blend. Consequently, characteristically distinct morphologies are formed in each PBTTT:fullerene blend dependent on the fullerene derivative that is used, with such changes having a clear

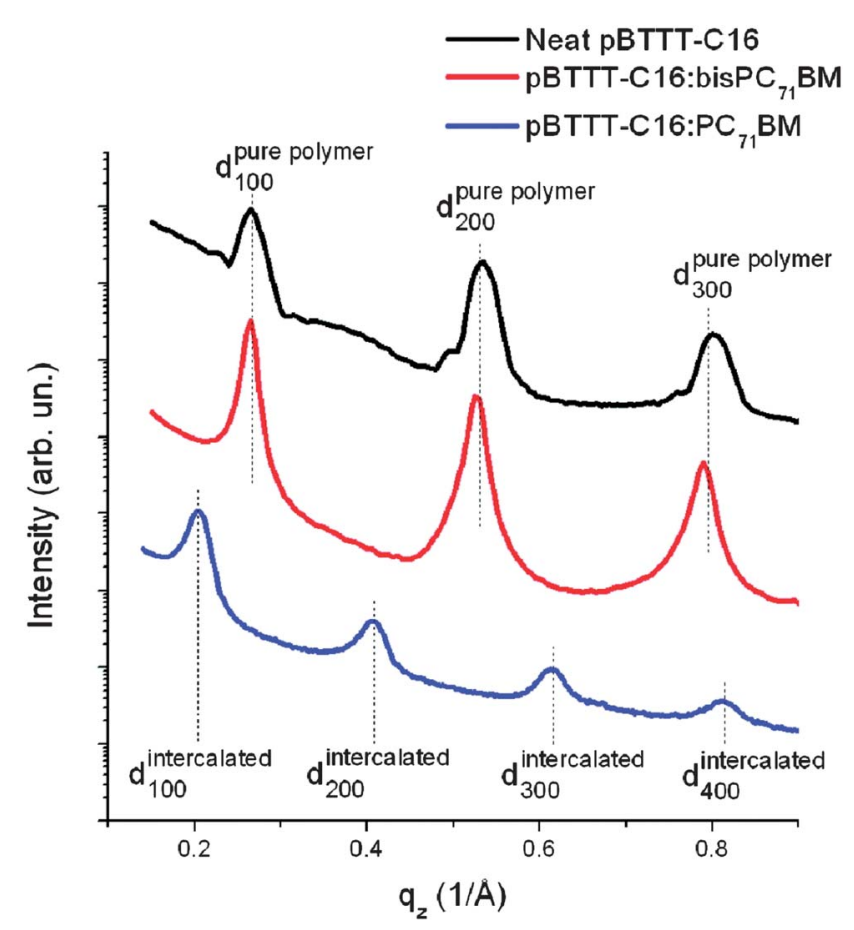

Fig. 17 Grazing-incidence wide-angle $X$-ray diffraction patterns for pure $p B T T T$ (black), $\mathrm{pBTTT}$ :bisPC $\mathrm{C}_{71} \mathrm{BM}$ (red), and $\mathrm{pBTTT}: \mathrm{PC}_{71} \mathrm{BM}$ (blue). Figure reproduced from ref. 112, Copyright (c) 2009, American Chemical Society. 
impact on the optimum film composition required to create a high-performance OPV device. From such structural studies, generalized molecular structures have been proposed for other systems in which the polymer is relatively less crystalline than PBTTT and are thus more difficult to characterize using X-ray diffraction techniques. Here, alternative techniques such as UV-VIS spectroscopy, DSC or solid-state NMR can also be applied to provide indirect insight into whether molecular mixing occurs in a polymer:fullerene blend. ${ }^{\mathbf{1 1 4 , 1 5}}$

The results reviewed in Sections 3 and 4 clearly illustrate that the molecular structure of both the polymer and the fullerene components have a significant influence on the physical and optoelectronic properties of a binary photovoltaic blend. However the design and preparation of BHJ OPV devices containing three different materials in the photoactive layer has also attracted growing interest. ${ }^{\mathbf{1 1 6}}$ In such ternary blend OPVs, a relatively small fraction of a semiconducting donor, ${ }^{117}$ acceptor, ${ }^{118}$ sensitizer, ${ }^{119}$ or block-polymer ${ }^{120}$ is added to a binary blend. Here, the third component (e.g. a semiconducting polymer) can extend the lightharvesting ability of the device if its optical absorption complements that of the primary polymer. The incorporation of the third component can also change the molecular order, or mixing and separation of the main components. Such morphology changes can be used to dramatically affect photo-physical processes and consequently modify device performance. However the presence of the third component in the $\mathrm{BHJ}$ layer increases the complexity of the 'parameter-space' associated with the choice of materials and processing conditions needed to optimize photovoltaic functionality. Until a rational design and optimization process has been reached, the benefit of such ternary blends cannot be fully realized. ${ }^{121}$ A description of the design rules and implications of BHJ OPVs based on ternary blends can be found in a number of dedicated reviews. ${ }^{\mathbf{1 2 2 - 1 2 4}}$

\section{Molecular conformation, phase separation and device performance upon thermal annealing}

Thermal annealing is a post film-deposition technique that can modify the morphology of polymer:fullerene blend thin-films and thus impact upon their photovoltaic properties. For example, in PSBTBT:PCBM solar cells, ${ }^{\mathbf{1 2 5 , 1 2 6}}$ thermal annealing can increase the crystallinity of PSBTBT and consequently improve charge carrier mobility. For many other copolymer systems however, thermal annealing has a negative impact upon OPV device efficiency. For example, in PCDTBT:PCBM devices, OPV PCE can be slightly improved only by thermal annealing below $\sim 80{ }^{\circ} \mathrm{C}$ however annealing above this temperature device efficiency is reduced. In devices based on many other low bandgap copolymers (for instance PBDTTPD ${ }^{127}$ ), thermal annealing even at relatively mild temperatures will reduce photovoltaic performance.

As many D-A copolymers are relatively amorphous and exhibit fine mixing with fullerene molecules, it is a challenge to unambiguously characterize the nanoscale morphology in these blends. Synchrotron-based grazing incidence X-ray scattering measurements are able to reveal subtle changes in structure in these low-order systems that result from thermal annealing. ${ }^{128}$ In Fig. 18a, a 2D GIWAXS image of a PCDTBT thin film prepared by spin-casting from CB is presented. ${ }^{\mathbf{1 2 9}}$ Here, it can be seen that $\pi-\pi$ stacking in the as-cast PCDTBT film is evidenced by a scattering 'crescent' observed at $q=1.57 \AA^{-1}$ in the out-of-plane direction. This indicates a preferential "face-on" $\pi$-stacked orientation of the polymer chains with respect to the silicon substrate. The inner diffraction ring, observed at $q_{z}=0.31 \AA^{-1}$ $(\sim 20 \AA)$ is attributed to $1^{\text {st }}$ order scattering from the PCDTBT backbones separated by two alkyl side-chains. Recent work ${ }^{\mathbf{1 3 0}}$ has shown that PCDTBT chains form lamellar structures with an "edge-on" orientation with respect to the plane of the film after thermal treatment. This is shown in Fig. 18b, in which a 2D GIWAXS scattering pattern from a PCDTBT thin film after thermal annealing at $200{ }^{\circ} \mathrm{C}$ is presented. Here, $2^{\text {nd }}$ and $3^{\text {rd }}$ order diffraction peaks from lamellar side-chain crystals at $q_{z}=$ $0.634 \AA^{-1}$ and $0.947 \AA^{-1}$ are observed in the out-of-plane direction. Several other off-axis peaks, located at $( \pm 0.150$, 0.186), $( \pm 0.150,0.494)$ and $( \pm 0.150,0.811) \AA^{-1}$, indicate extended long-range order along the backbone direction of the crystallites. ${ }^{\mathbf{1 3 0}}$ We note that the development of "edge-on" lamellar crystals may well be determined by the temperature and kinetics of the thermal annealing treatment, and also by the
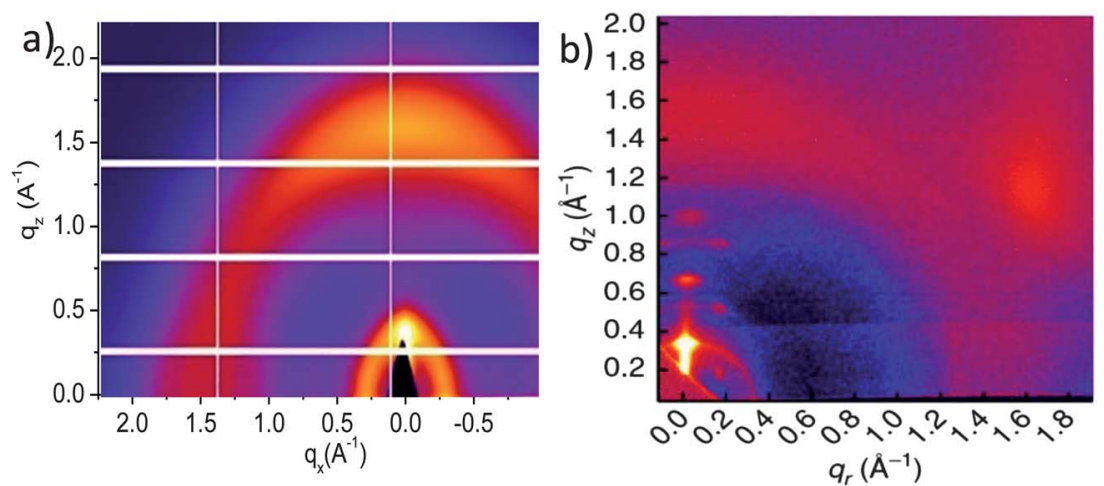

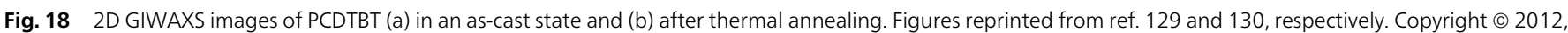
Nature Publishing Group. 
molecular weight of the polymer. Nevertheless, the molecular structure in PCDTBT films upon thermal treatment above the bulk $T_{\mathrm{g}}$ is described by a combination of "face-on" $\pi-\pi$ stacking and "edge-on" lamella ordering. ${ }^{128,130}$ Additional insight into nanostructure in PCDTBT thin-films can be obtained using GIWAXS performed as a function of X-ray beam grazing incidence angle, providing a degree of depth resolution below the film surface. ${ }^{\mathbf{1 2 9}}$ It was shown that lamellar ordering in annealed PCDTBT thin films mainly occurs close to the film-surface, whilst $\pi-\pi$ stacking is more pronounced toward the substrate interface. ${ }^{129}$ A key finding from this study was the demonstration that vertical heterogeneity in molecular structure can exist in PCDTBT thin-films, with the extent of such variations influenced by the surface and substrate interface.

Studies on PCDTBT ${ }^{128,131}$ have shown that the overall degree of $\pi-\pi$ stacking in a thin-film reduces upon annealing, with such changes affecting the charge transport properties of the material (see Fig. 19). In an OPV device, charges are ideally transported between the electrodes in a direction perpendicular to the substrate. Consequently, "face-on" $\pi-\pi$ stacking with respect to the device substrate is generally more favorable for efficient charge carrier transport than "edge-on" lamellar packing as the distance between $\pi-\pi$ stacked molecules $(\sim 4 \AA)$ is significantly smaller than the distance between lamellae $(\sim 20 \AA)$. Changes in molecular structure of the polymer phase are therefore likely to be partly responsible for reduced out-ofplane charge mobility in PCDTBT: $\mathrm{PC}_{71} \mathrm{BM}$ blend thin-films upon thermal annealing around the bulk $T_{\mathrm{g} \cdot{ }^{131}}$ Further reductions in photovoltaic performance are found when higher annealing temperatures (at or above the $T_{\mathrm{g}}$ of $\mathrm{PC}_{71} \mathrm{BM}$ at $\sim 155$ ${ }^{\circ} \mathrm{C}$ ) are applied. ${ }^{\mathbf{1 3 1}}$ In this regime, the thermally activated diffusion rate of $\mathrm{PC}_{71} \mathrm{BM}$ increases substantially and $\mathrm{PC}_{71} \mathrm{BM}$ molecules may aggregate to form micron-scale crystallites. ${ }^{\mathbf{1 3 1}}$ The aggregation and crystallization of $\mathrm{PC}_{71} \mathrm{BM}$ reduces the fullerene concentration in the bulk of the blend film and consequently reduces the volume of interfaces with PCDTBT. It was suggested therefore that the morphological coarsening of the blend reduced device PCE by decreasing the efficiency of photogenerated charge separation and increasing chargecarrier recombination.
Recent work ${ }^{\mathbf{1 2 7}}$ on PBDTTPD:PC ${ }_{61} \mathrm{BM}$ blend thin-films has also found that lamellar ordering of the polymer increases and $\pi-\pi$ stacking decreases after the film has been subject to thermal annealing; an effect similar to those observed in PCDTBT. Here however, it was found that the SCLC hole mobility in PBDTTPD was not significantly affected by annealing. ${ }^{127}$ The authors attributed the relatively lower PCE of thermally annealed devices to reduced miscibility between PCBM and PBDTTPD that led to the formation of morphological charge traps. Studies on OPV blends of poly(thienothiophene benzodithiophene) (PTB1) and PCBM have also demonstrated that thermal annealing reduces device efficiency. ${ }^{\mathbf{1 3 2}}$ Here, GIWAXS measurements revealed that thermal annealing enhances $\pi-\pi$ stacking between PTB1 chains, with these chains adopting a "face-on" orientation with respect to the film substrate. However, thermal annealing also resulted in the formation of relatively large PCBM domains having a size between 10 and $200 \mathrm{~nm}$. This morphology - often described as 'overly coarse phase-separation' - is believed to reduce the efficiency of charge separation and was identified as the origin of the reduced device PCE.

In summary, although thermal annealing has been demonstrated to enhance the photovoltaic performance of solar-cell devices utilizing semi-crystalline copolymers (such as PSBTBT), it does not generally improve performance of devices based on amorphous copolymer blends. ${ }^{133,134}$

\section{Molecular conformation, phase separation and device performance controlled via solvent processing}

In this section, we review experiments designed to control the state of order and phase separation in D-A copolymer fullerene blends through solvent processing. The solvent processing described here includes the use of different solvents, solvent mixtures, solvent additives and solvent vapor annealing.

Polymer and fullerene components used in a BHJ often have a different solubility in different solvents. The use of different types of solvent or a mixture of solvents to dissolve a
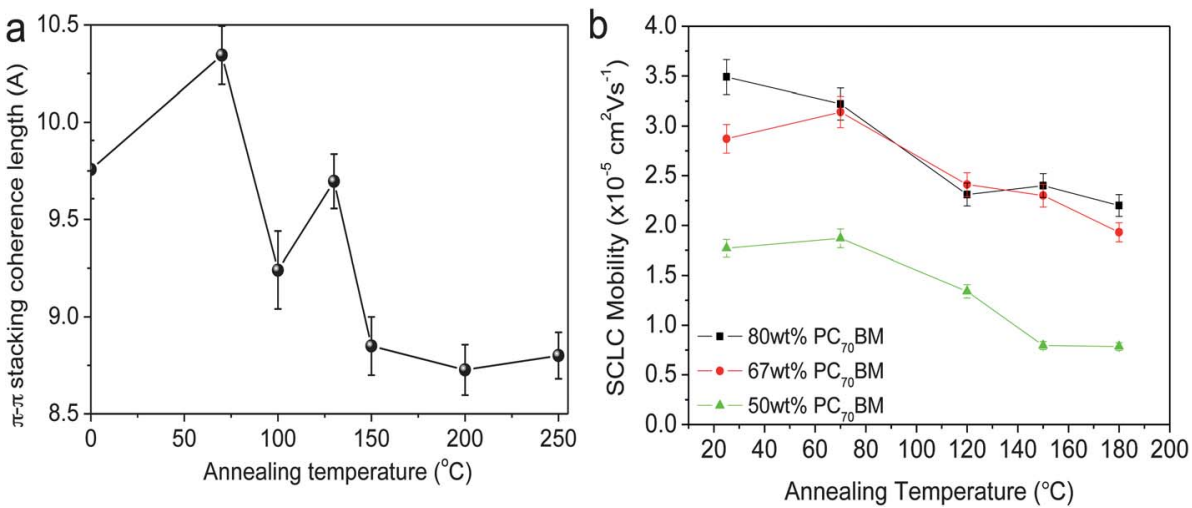

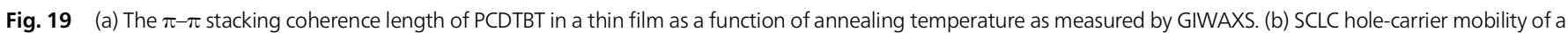
PCDTBT:PC ${ }_{71}$ BM thin-film device as a function of annealing temperature (annealing time of 30 minutes). Figure reprinted from ref. 131 , Copyright $@ 2012$ WILEY-VCH. 
polymer:fullerene blend has been widely used to control the nanoscale morphology of the blend on casting from solution, with such blend morphology having a clear impact on device performance. ${ }^{135,136}$ Fig. 20 shows the effect of casting solvent on film morphology and device performance for a PCDTBT:PC ${ }_{71} \mathrm{BM}$ blend solar cell. ${ }^{135}$ It can be seen that large clusters of $\mathrm{PC}_{71} \mathrm{BM}$ aggregates are present in films cast from $\mathrm{CF}$ and $\mathrm{CB}$, whereas fine-scale phase separation occurs in the film cast from DCB. Such structure is present at the film surface (as measured by AFM) and in the bulk (as measured by TEM). It was found that OPV devices fabricated with the active layer cast from DCB had both the highest internal photocurrent efficiency (IPCE) and external device efficiency.

The use of solvent mixtures to cast a photovoltaic blend film has been found to exert a dramatic influence on the molecular packing of each material and the overall BHJ morphology. This is shown in the schematic illustration presented in Fig. 21 which describes a blend of the materials PDPP3T:PC ${ }_{71}$ BM. $^{137}$ When the blend is cast from DCB, the film is characterized by large, impure (mixed) domains separated by rough interfaces. The addition of $20 \%$ CF to DCB however leads to a remarkable increase in domain purity that is accompanied by reduced domain size and sharper interfaces. On addition of $5 \%$ of the solvent additive 1,8-diiodooctane (DIO) to the DCB/CF solvent, the interface between domains becomes rougher, however the size of the domains is not apparently affected. Furthermore grazing incidence X-ray scattering shows that pronounced diffraction peaks of the PDPP3T component are observed due to improved lamellar order. ${ }^{137}$ Ternary mixed solvents treatment can thus be used to improve molecular morphology for OPV applications through the formation of long-range ordered structures having favorable, pure domains characterized by rough domain interfaces. As a result, the PCE of PDPP3T:PC ${ }_{71} \mathrm{BM}$ solar cells was improved from 4.87 to 5.38 and then to $6.71 \%$, when the blends were cast from DCB, DCB/CF and $\mathrm{DCB} / \mathrm{CF} / \mathrm{DIO}$, respectively. ${ }^{137}$

The differing solubility of the polymer and fullerene components in solvent mixture can also lead to the formation of a film morphology characterized by multiple length-scales. For example the polymer pDPP dissolves well in the low boiling point solvent $\mathrm{CF}$, but is less soluble in higher boiling point solvent DCB. In contrast however, $\mathrm{PC}_{71} \mathrm{BM}$ is more soluble in $\mathrm{DCB}$ compared to $\mathrm{CF}$. Therefore if a pDPP: $\mathrm{PC}_{71} \mathrm{BM}$ blend film is cast from a $\mathrm{DCB} / \mathrm{CF}$ solvent mixture, ${ }^{\mathbf{1 3 8}}$ the initial rapid evaporation of the lower boiling point $\mathrm{CF}$ causes the pDPP to become relatively less soluble, causing it to crystallize. The $\mathrm{PC}_{71} \mathrm{BM}$ however remains solvated as the casting solvent contains a significant fraction of DCB. As a result of this, the dried film is characterized by a crystalline fibrillar network composed of pDPP that is surrounded by fine-scale phase-separated $\mathrm{pDPP} / \mathrm{PC}_{71} \mathrm{BM}$ morphology formed during the latter stages of the film drying process.

The addition of a few vol\% of a solvent additive to the primary casting solvent has been demonstrated to be an effective means to improve the PCE of BHJ OPVs made from D-A copolymers. $^{139}$ For example, OPVs made from PCPDTBT:PC ${ }_{71} \mathrm{BM}$ had a PCE of 2.7 to $3.5 \%$ without the inclusion of any type of solvent additive. ${ }^{\mathbf{1 4 0 , 1 4 1}}$ However by incorporating a small amount of alkanedithiol as an additive to the primary solvent (chlorobenzene), the PCE was increased to $5.5 \%$. In other work, PDTSTPD:PC ${ }_{71} \mathrm{BM}$ OPV devices processed using the additive DIO (at 3\% by volume) have yielded device PCEs close to 7.3\%; a dramatic increase over PCEs of less than $1 \%$ when no additive is used (see Fig. 22). ${ }^{142}$ It is worthwhile to note that with the addition of DIO, a PCE of $6.1 \%$ can be
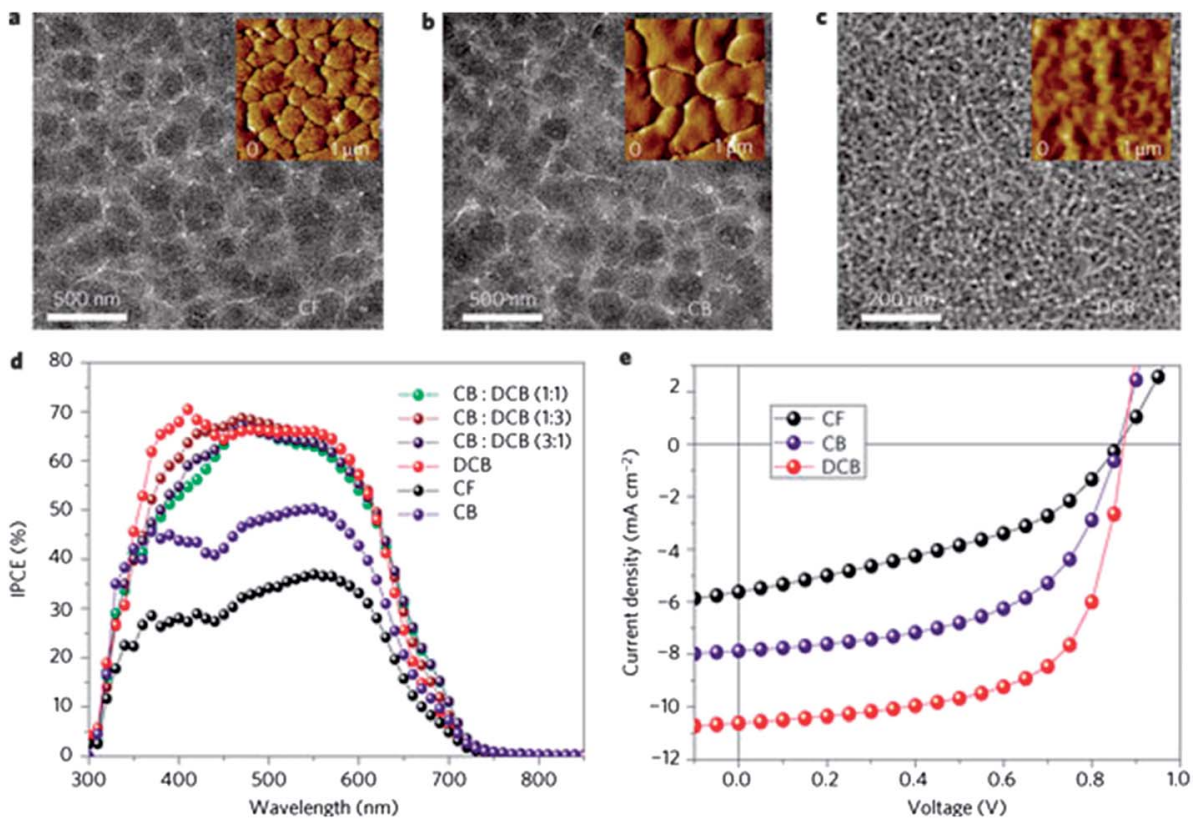

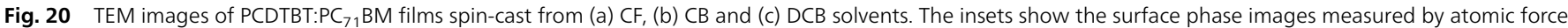

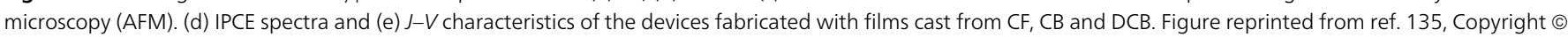
2009, Nature Publishing Group. 
(a) Single Solvent (DCB)

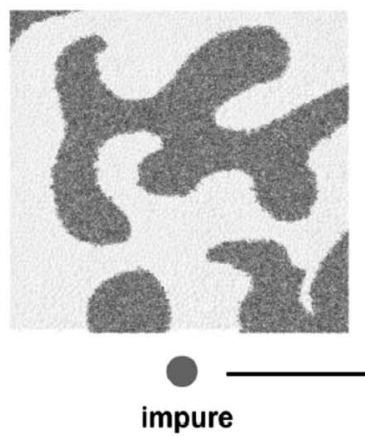

(b) Binary Solvent (DCB/CF)

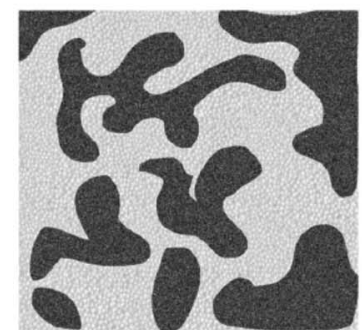

(c) Ternary Solvent (DCB/CF/DIO)

\begin{tabular}{|c|ccc|}
\hline $\begin{array}{c}\text { Polymer domain } \\
\text { Size } \\
\text { Purity } \\
\text { Interface }\end{array}$ & $\begin{array}{c}D C B \\
\text { big } \\
\text { poor } \\
\text { blurry }\end{array} \Longrightarrow \begin{array}{c}D C B / C F \\
\text { small } \\
\text { good } \\
\text { sharp }\end{array} \Longrightarrow \begin{array}{c}D C B / C F / D / O \\
\text { small } \\
\text { better } \\
\text { blurry }\end{array}$ \\
\hline
\end{tabular}

Fig. 21 Schemes of morphology evolution in PDPP3T/PC 71 BM blend films cast using different solvents. Figure reprinted from ref. 137, Copyright $\odot 2012$ WILEY-VCH.
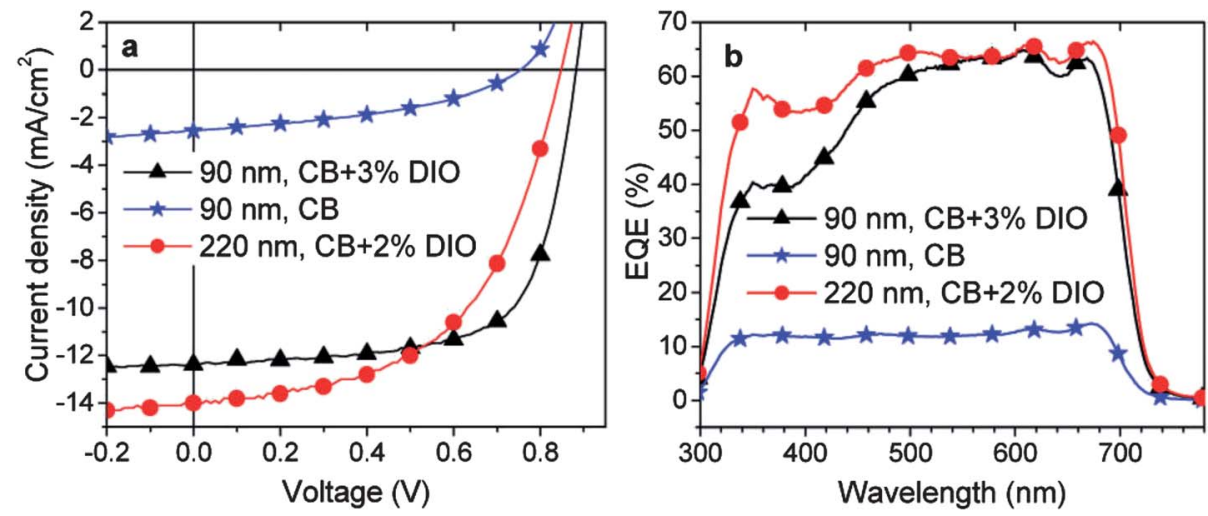

Fig. 22 (a) $J-V$ and (b) EQE curves of solar cells made from PDTSTPD:PC ${ }_{71} B M(1: 2)$ blend with/without the presence of solvent additive DIO at different thickness of the active layer. Figure reprinted from ref. 142, Copyright $\odot 2011$ American Chemical Society.

obtained in OPV devices having an area of $1.0 \mathrm{~cm}^{2}$ even when the active layer is $220 \mathrm{~nm}$ thick.

In order for a solvent additive to modify the morphology of BHJ polymer:fullerene blend thin-films during the film-casting process, it must exhibit a higher boiling point than the primary solvent and also a preferential solubility for PCBM. ${ }^{143,144}$ This effect has been studied in detail using D-A copolymers such as PTB7, ${ }^{145}$ PBTTPD, ${ }^{24}$ PCPDTBT, ${ }^{144,146,147}$ PDPPTPT, ${ }^{148}$ PSi and PGe. ${ }^{149}$ Here, the use of techniques that probe the structure of such blend thin-films has demonstrated that solvent additives can significantly alter the nanoscale morphology of the bulk heterojunction system. Indeed, solvent additives are able to reduce the size of fullerene domains or improve their average state of structural order. For example, TEM studies of PBTTPD: $\mathrm{PC}_{71} \mathrm{BM}$ blend thin-films has revealed a reduction in fullerene domain size from $150 \mathrm{~nm}$ to $\sim 30 \mathrm{~nm}$ upon addition of the additive diiodohexane (DIH) to the casting solution. ${ }^{24}$ This effect can also be seen in the TEM images presented in Fig. 23, where a relatively finely mixed morphology was observed in a PTB7:PC ${ }_{71} \mathrm{BM}$ blend thin-film upon on addition of $3 \mathrm{vol} \%$ diiodooctane (DIO) to the casting solution. ${ }^{145}$ Resonant soft X-ray scattering (R-SoXS) measurements suggested that a fullerene domain size of $177 \mathrm{~nm}$ in PTB7: $\mathrm{PC}_{71} \mathrm{BM}$ blend films cast from $\mathrm{CB}$ was reduced to $\sim 34 \mathrm{~nm}$ when DIO was added to the casting solvent. ${ }^{150}$ In a related study, transmission SAXS measurements on solution samples revealed that DIO can selectively dissolve PCBM aggregates in a PTB7: $\mathrm{PC}_{71} \mathrm{BM}$ blend solution, permitting the formation of a more finely mixed blend morphology when the solution is cast into a thin-film. ${ }^{151}$ GIWAXS has been used to study the modification of blend structure at a molecular length-scales resulting from the incorporation of a solvent additive. Here it was found that the PTB7 lamellar $d$-spacing underwent a small increased from 17.1 to $18.9 \AA$ A relative to a blend film that was cast without the DIO additive. However, no substantial changes in the length-scale of either PTB7 $\pi-\pi$ stacking or the packing of PCBM molecules was identified.

Solution processing additives can result in an increased degree of polymer crystallinity. This has been demonstrated using GISAXS/GIWAXS in PBTTPD:PC ${ }_{71} \mathrm{BM}$ blends upon the addition of DIH to the primary casting-solvent chloroform 

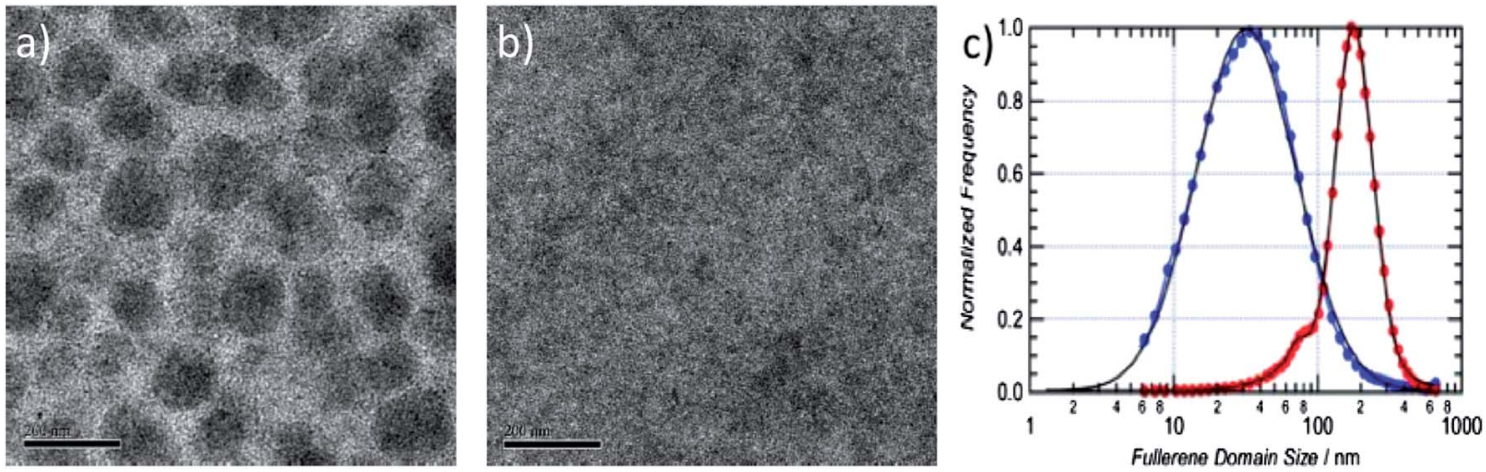

Fig. 23 TEM images of PTB7/PC 71 BM (1: 1.5) films cast (a) without and (b) with the additive DIO. Scale bar $200 \mathrm{~nm}$. (c) Normalized histogram of scattering intensity versus fullerene domain size in PTB7/PC 71 BM with (blue curve) and without (red curve) DIO as measured by R-SoXS. Figures reprinted from ref. 145 and 150 , Copyright (c) WILEY-VCH.

(CF). ${ }^{24}$ This conclusion was also confirmed in a second study where the polymer PCPDTBT was found to crystallize through the presence of solvent additives. ${ }^{143,152-154}$ Using time-resolved GIWAXS, Rogers et al. ${ }^{153}$ observed a lower nucleation barrier for PCPDTBT crystallization upon addition of octanedithiol (ODT) to the primary casting solvent, thereby encouraging crystallite growth over an extended timescale. This effect is illustrated in Fig. 24, where GIWAXS scattering patterns from a PCDPTBT:PC ${ }_{71} \mathrm{BM} 1: 3 \mathrm{wt} \%$ blend film cast from $\mathrm{CB}$ or $\mathrm{CB} / \mathrm{ODT}$ after 78 minutes after spin casting is shown. Here, it can be seen that films cast from $\mathrm{CB} / \mathrm{ODT}$ solutions show pronounced Bragg scatter originating from the (100) plane of semi-crystalline PCPDTBT. As demonstrated in an earlier study, the crystallization of PCPDTBT is unimpeded by the presence of PCBM, which - as a result of the solvent additive - remains relatively welldissolved in solution. ${ }^{152}$ This suggested that the additive facilitates the formation of a multi-length scale morphology comprising domains of pure, crystalline PCPDTBT fibrils and a PCBM-rich mixture containing amorphous PCPDTBT. ${ }^{152}$ It was argued that the formation of such structures was not possible via conventional thermal annealing techniques as polymer selforganization is inhibited by the simultaneous thermally activated diffusion of PCBM molecules. Accordingly, the morphology formed by solvent mixtures can (to a certain extent) be described as being 'non-equilibrium' in nature. ${ }^{152}$
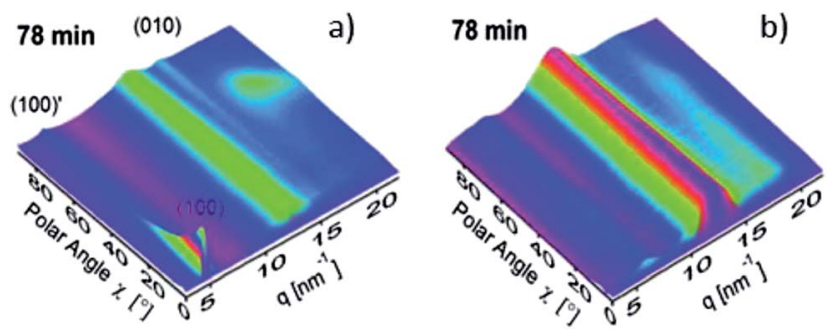

Fig. $243 \mathrm{D}$ sector plots of PCPDTBT:PC $\mathrm{F}_{71} \mathrm{BM}$ blends cast from $\mathrm{CB}$ containing (a) $3 \%$ or (b) $0 \%$ ODT after 78 min of spin-coating, showing the scattered intensity vs. polar angle $\chi$ and scattering vector $q$. Figure reprinted from ref. 153, Copyright (c) 2012, American Chemical Society.
Although it has often been observed that the use of solvent additives can improve the PCE of an OPV device. This is, however, not true in some cases. For example, the addition of DIO to a PCBM blend containing a $N$-alkylthieno[3,4-c]pyrrole-4,6-dione (TPD)-based polymer having linear side-chains only had a marginal effect on OPV properties. ${ }^{155}$ This finding was explained on the basis that the copolymer already forms relatively ordered structures when cast from the primary solvent. In other work it was shown that the addition of 3 vol\% DIO to the primary castingsolvent $(\mathrm{CB})$ results in a relatively large increase in the PCE of a PDTSTPD/PC $\mathrm{PC}_{71} \mathrm{BM}$ blend OPV (from below $1.0 \%$ to $7.3 \%$ ), however such effects are less pronounced when the primary solvent is switched to DCB. ${ }^{142}$ A similar conclusion has also been reached when DIO was used as an additive in a DCB-cast PTB7/ $\mathrm{PC}_{71} \mathrm{BM}$ blend device. ${ }^{145}$ It is clear therefore that there is a complex interdependence between the nature and properties of the additive, the polymer and the primary casting solvent.

Subjecting photovoltaic blends to a solvent vapor is a technique that can also be used to tune the nanoscale morphology and thus modify OPV device performance. ${ }^{61,156}$ For example, it was found that an interpenetrating network having nanoscale phase separation can be created in PCDTBT:PC ${ }_{71} \mathrm{BM}$ blend by annealing it in a mixed solvent vapor comprising a 1:1 blend of THF: $\mathrm{CS}_{2}$ for 5 minutes. ${ }^{157}$ Here, the $\mathrm{CS}_{2}$ vapor is a good solvent for PCDTBT and thus helps to improve both crystallinity and degree of $\pi-\pi$ stacking within the PCDTBT phase; a conclusion reached on the basis of X-ray measurements. TEM studies of the same blend also demonstrated the ability of the PCDTBT phase to self-organize to form nanofibrils. However the THF component of the vapor induced the $\mathrm{PC}_{71} \mathrm{BM}$ to form aggregates and to phase separate from the mixed phase, with the $\mathrm{CS}_{2}$ vapor preventing the formation of excessively large aggregates. As a result, the efficiency of vapour annealed devices increased from 4.5 to $6.6 \%$; an increase in efficiency by more than $40 \%$ over that of the untreated device.

\section{Vertical stratification of PCBM in copolymer solar cells}

Vertical stratification of electron donors and acceptors within a $\mathrm{BHJ}$ layer can be induced during the film casting process or 
during the application of post film-deposition annealing treatments. The degree of stratification is often determined by the molecular interactions between the polymer chains and the fullerene molecules, and by the interactions between these materials and the film substrate. In an OPV device, vertical stratification is often believed to have an important influence on the efficiency of charge transport within the BHJ layer and the eventual extraction of charge at the electrode interfaces. For example, a relatively high concentration of the hole-transporting polymer at the cathode interface will impede electron extraction, whereas an enriched layer of electron-transporting fullerenes at the anode interface will reduce the efficiency of hole extraction by acting as a charge recombination centre. A number of techniques have been used to characterize chemical composition at or close to the surface of a film, including nearedge X-ray absorption fine-structure (NEXAFS) ${ }^{158}$ and X-ray photoelectron spectroscopy (XPS). ${ }^{159}$ Other techniques have been used to probe the entire depth profile of the components in a blend including neutron reflectivity (NR) ${ }^{160} \mathrm{X}$-ray reflectivity (XRR), ${ }^{161}$ spectroscopic ellipsometry (SE) ${ }^{162}$ and dynamic secondary ion mass spectrometry (DSIMS). ${ }^{126}$

Using XPS Felicissimo et al. ${ }^{159}$ detected an enriched polymer layer at the film surface in an F8DTBT: $\mathrm{PC}_{61} \mathrm{BM}$ blend. DSIMS and NEXAFS were used by Anselmo et al. ${ }^{158}$ to study the vertical profile of donor-acceptor polyfluorene copolymers blended with $\mathrm{PC}_{61} \mathrm{BM}$, and also evidenced an enrichment layer of polymer near the film surface. Here, the purity of the enrichment layer improved as the polar nature of the polymer was increased. Lu et al. ${ }^{126}$ reported a PSBTBT enriched-layer at the film surface in an as-cast PSBTBT:PC ${ }_{61} \mathrm{BM}$ blend films. In this system, it was found that thermal annealing promoted the segregation of PSBTBT to the film surface in the absence of a cathode layer (see Fig. 25a), however this process was apparently reversed, with migration of $\mathrm{PC}_{61} \mathrm{BM}$ toward the top surface observed when the blend film was annealed in the presence of a cathode (see Fig. 25b).

The vertical stratification of PCBM in PCDTBT:PC ${ }_{61} \mathrm{BM}$ blend films has been studied using NR. ${ }^{160}$ Here, it was shown that there was an enrichment of PCBM at the film surface in an as-cast PCDTBT:d5-PC ${ }_{61} \mathrm{BM} 1: 4 \mathrm{wt} \%$ blend spin-cast on a PEDOT:PSS anode film. At the interface with the anode, there was also a relative depletion of the fullerene, effectively constituting an enriched PCDTBT layer. ${ }^{160}$ Such a distribution of donor and acceptor materials is ideal in OPV devices fabricated in a standard geometry (cathode on top), since efficient charge extraction is facilitated by the enrichment of the electron accepting material when it is located close to the cathode. A follow-on NR study probed the generality of this vertical structure by measuring the depth composition of PCDTBT-8: $\mathrm{PC}_{71} \mathrm{BM}$ (defined as $\mathrm{P1}: \mathrm{PC}_{71} \mathrm{BM}$ in ref. 163) and PCDT2BT-8:PC ${ }_{71} \mathrm{BM}$ (defined as $\mathrm{P} 2: \mathrm{PC}_{71} \mathrm{BM}$ in ref. 163) $1: 4 \mathrm{wt} \%$ blend thin films spray-cast onto a heated PEDOT:PSS substrate. ${ }^{163}$ It was found that the vertical stratification observed was qualitatively similar to that seen in PCDTBT:PC ${ }_{71}$ BM. This can be seen in Fig. 26,
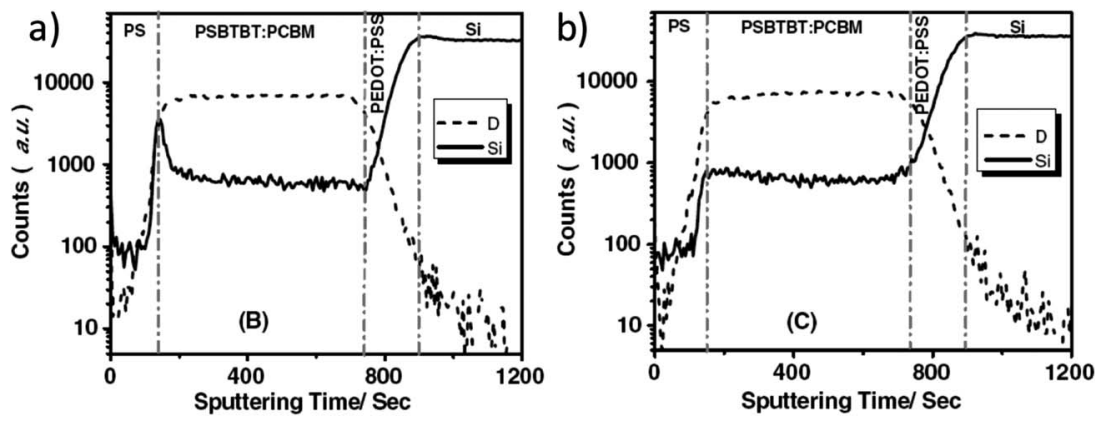

Fig. 25 DSIMS profile of PSBTBT:PC 61 BM blend films annealed at $150^{\circ} \mathrm{C}$ for $1 \mathrm{~min}(\mathrm{a})$ before and (b) after the deposition of the Al cathode. Figure reprinted from ref. 126, Copyright $\odot 2011$ WILEY-VCH.
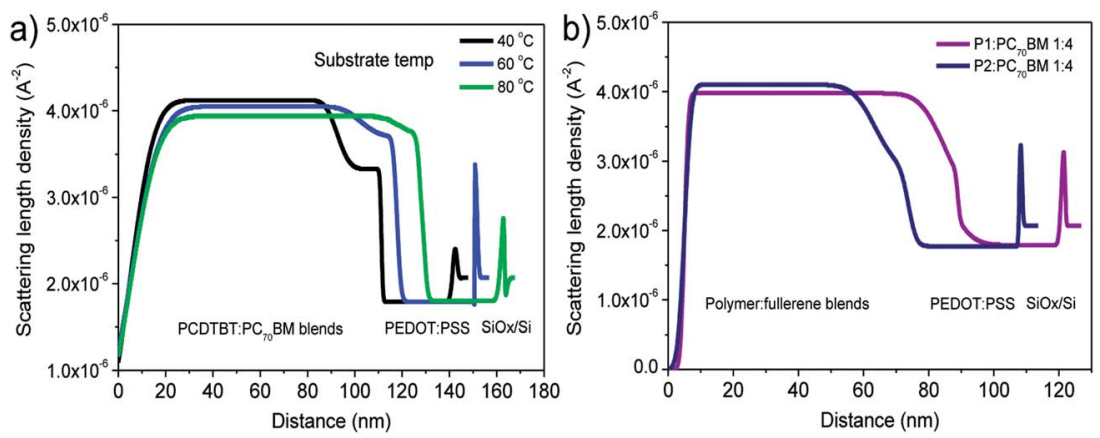

Fig. 26 (a) Scattering length density (SLD) profiles of PCDTBT:PC ${ }_{71} B M(1: 4)$ blends deposited by spray-coating at three different substrate temperatures from a $C B$ solution. (b) SLD profiles of $\mathrm{P1}: \mathrm{PC} \mathrm{C}_{11} \mathrm{BM}$ and $\mathrm{P2}: \mathrm{PC} \mathrm{C}_{71} \mathrm{BM}$ blends deposited by spray-coating at a substrate temperature of $40{ }^{\circ} \mathrm{C}$ from a $\mathrm{CB}$ solution. The thicknesses of the blend films are slightly different for all samples. Figures reprinted from ref. 163, Copyright @ 2013 WILEY-VCH. 
where for films spray-cast onto a substrate held at $40{ }^{\circ} \mathrm{C}$, it is apparent that there is a region close to the PEDOT:PSS interface in which the $\mathrm{PC}_{71} \mathrm{BM}$ concentration is relatively deficient. The degree of vertical stratification observed is apparently dependent on the temperature of the underlying substrate during film drying. For a substrate temperature of $40{ }^{\circ} \mathrm{C}$, the average width and relative weight concentration of the $\mathrm{PC}_{71} \mathrm{BM}$ depleted region was $17 \mathrm{~nm}$ and $65 \mathrm{wt} \%$ respectively. At a substrate temperature of $60{ }^{\circ} \mathrm{C}$, the $\mathrm{PC}_{71} \mathrm{BM}$ concentration in the deficient region increased to $78 \mathrm{wt} \%$ whilst the width of this region decreased to $13 \mathrm{~nm}$. For blend films cast onto a substrate held at $80{ }^{\circ} \mathrm{C}$ the deficient region was almost completely suppressed, indicating a relatively homogeneous distribution of $\mathrm{PC}_{71} \mathrm{BM}$ throughout the entire depth of the blend film. This clearly demonstrates the possibility to alter vertical stratification in these blend films by accelerating the film casting process though the use of a heated substrate.

Although there are large number of D-A copolymers that have been demonstrated to be very promising electron donating materials, there has only been a limited amount of work reported that addresses the extent of vertical stratification in a $\mathrm{BHJ}$ active layer and its consequence for efficient OPV operation. At present, more work is needed to fully explore the effects of free energy of each component, the role of polymer-fullerene and blend-substrate interactions as well as the film drying kinetics on driving vertical distribution of the different blend components. We believe that such studies will help to establish a clear correlation between the vertical component distribution and device performance.

\section{Morphological stability}

The stability of the active layer morphology and the electrode interfaces have a dramatic influence on the operational lifetime of a solar cell device. As the active layer of a polymerfullerene BHJ solar cell is prepared from solution, a few percent of casting solvent can become trapped within the film during the film drying process. ${ }^{131}$ Such residual solvents can induce the diffusion and aggregation of the PCBM component, and ultimately affect the stability of the film morphology. ${ }^{164}$ Residual solvents often can only escape from a solid blend film very slowly as their evaporation is opposed by the slow volumerelaxation of the glassy film. ${ }^{165}$ Ye et al. demonstrated that by washing a photovoltaic blend with a low boiling-point inert solvent (such as methanol), it was possible to remove unwanted solvent additives. ${ }^{\mathbf{1 6 6}}$ Here, the removal of high boiling point solvent additives has been found to enhance device performance and morphological stability. This method has proved to be effective in a number photovoltaic blends of $\mathrm{PC}_{71} \mathrm{BM}$ incorporating different donor polymers.

Another technique used to remove trapped, residual solvent is to heat a blend film at a temperature above the $T_{\mathrm{g}}$ of the blend or the boiling temperature of the specific solvent. ${ }^{16,131}$ However heating at high temperatures increase the diffusion coefficient of PCBM and encourages aggregation. ${ }^{\mathbf{1 3 1}}$ Once the size of the PCBM aggregates and the extent of phase separation becomes too coarse, detrimental effects can occur to limit device efficiency. ${ }^{\mathbf{1 2 7 , 1 3 1}}$ Recent work has demonstrated that low-level light exposure (with an illumination intensity $\sim 10 \mathrm{~mW} \mathrm{~cm}^{-2}$ ) before low-temperature thermal annealing can be used to significantly increase the thermal stability of PCDTBT: $\mathrm{PC}_{61} \mathrm{BM}$ solar cell devices. ${ }^{\mathbf{1 6 7}}$ Here, the enhanced stability upon light exposure was suggested to result from the dimerization or oligomerization of $\mathrm{PC}_{61} \mathrm{BM}$; an effect assumed to slow down the diffusion and crystallization of PCBM under thermal stress. ${ }^{168} \mathrm{It}$ was suggested that the effect was more effective in a $\mathrm{PC}_{61} \mathrm{BM}$ based-blend compared to that containing $\mathrm{PC}_{71} \mathrm{BM}$, as $\mathrm{C}_{60}$ has greater tendency to undergo photo-induced crosslinking. ${ }^{\mathbf{1 6 7}}$ However a different study on a blend of PDTSTzTz:PC ${ }_{61} \mathrm{BM}$ found that the charge carrier mobility in an OPV device underwent a significant reduction upon light exposure (with an illumination intensity $\sim 100 \mathrm{~mW} \mathrm{~cm}^{-2}$ ) caused by the opticallyinduced dimerization of $\mathrm{PC}_{61} \mathrm{BM} .{ }^{169}$ The same study also reported that photo-induced dimerization did not occur in the fullerene derivative bisPC $_{61} \mathrm{BM}$.

Poly(3,4-ethylenedioxythiophene):polystyrene sulfonate (PEDOT:PSS) is widely used as the hole transporting layer in organic solar cells. However its acidic and hygroscopic nature make it susceptible to degradation, but also can result in the degradation of the active semiconductor layer and the device electrodes. ${ }^{\mathbf{1 7 0}}$ Furthermore, the adsorption and transport of moisture by the PEDOT:PSS anode-buffer into the active layer can also enhance ionic conduction of the active layer and accelerate corrosion. ${ }^{171} \mathrm{~A}$ cross-sectional TEM study reported by Suh et al. showed that the Ag electrode layer was degraded into particles of $\sim 10 \mathrm{~s}$ of $\mathrm{nm}$ over time in an inverted solar cell comprising of Ag/PEDOT:PSS/P3HT:PCBM/TiO $2 /$ ITO/glass. ${ }^{170}$ It was speculated that the water absorbed by the PEDOT:PSS layer caused corrosion at grain boundaries within the $\mathrm{Ag}$ layer. Indeed, it has been shown that by replacing PEDOT:PSS with a more air-stable hole-transporting layer (such as MoOx), the operational life-time of an OPV can be increased. ${ }^{172}$

While the use of alternative electrode materials having greater stability is an effective way to improve interface stability, the stability of the active layer requires the use of stable electron-donor and -acceptor materials. ${ }^{173}$ The synthesis of new polymers for high efficiency thus needs to also combine high stability on exposure to oxygen, water, and light as well as to thermal stress, as described in a guide to the role of the polymer structure on determining photochemical stability. ${ }^{\mathbf{1 7 4}}$ Other approaches to increasing the morphological stability of the active layer by cross-linking the polymer ${ }^{175,176}$ or the fullerene ${ }^{177}$ have also been proposed.

\section{Incorporation of interlayers in copolymer solar cells}

The incorporation of an interlayer between the polymer:fullerene active layer and the electrodes has been demonstrated to be an efficient approach to improve the PCE of various D-A copolymer solar cells. ${ }^{178}$ Conjugated polyelectrolytes, uncharged conjugated polymers, saturated polymers and small organic molecules have all been employed as an interlayer material. The mechanism behind such improvements has often been 
assigned to changes of electronic and orbital interactions at the interface. In this section, we discuss the use of such interface materials with D-A copolymer blends (see chemical structures in Fig. 27) and highlight cases where significant improvements in OPV device efficiency have been gained.

He et al. ${ }^{179}$ reported simultaneous enhancement of $V_{\mathrm{oc}}, J_{\mathrm{sc}}$ and FF in OPVs made by incorporating the alcohol/watersoluble conjugated polyelectrolyte PFN between the cathode and the active layer. As a result, OPV PCEs of 6.79\% and $8.37 \%$ were achieved using PCDTBT and PTB7 polymer:fullerene blends. Scanning Kelvin probe microscopy measurements indicate that in this system a microscopic electric dipole exists at the interface. This particular dipole alignment enhances the built-in potential and was estimated to be $0.3 \mathrm{~V}$ for $5 \mathrm{~nm}$ thick PFN layer. This enhanced built-in potential can improve chargeextraction, reduce the buildup of space-charge, and thus reduce recombination. The effective work-function of the ITO anode after coating a PFN interlayer has been found to reduced from 4.7 to $4.1 \mathrm{eV}$ from X-ray photoelectron spectroscopy measurement. ${ }^{3}$ A PCE of $9.2 \%$ could be obtained by incorporating a PFN a)

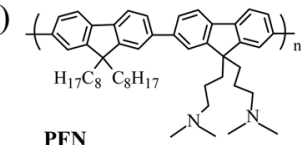

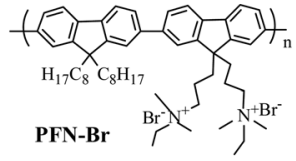<smiles>COP(=O)(O)CCCn1c2ccccc2c2ccccc21</smiles>

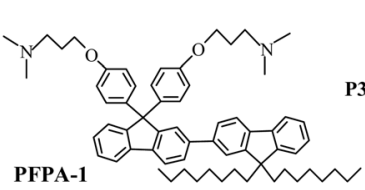

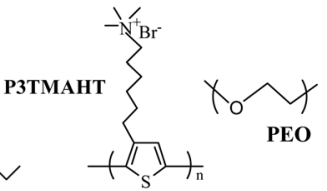

PFPA-1

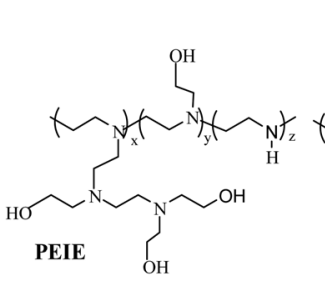<smiles>CCCN=CCNCCNCCNCCN</smiles>

PEI<smiles>CN(CCN)CCN</smiles>

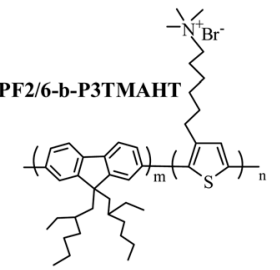

b)

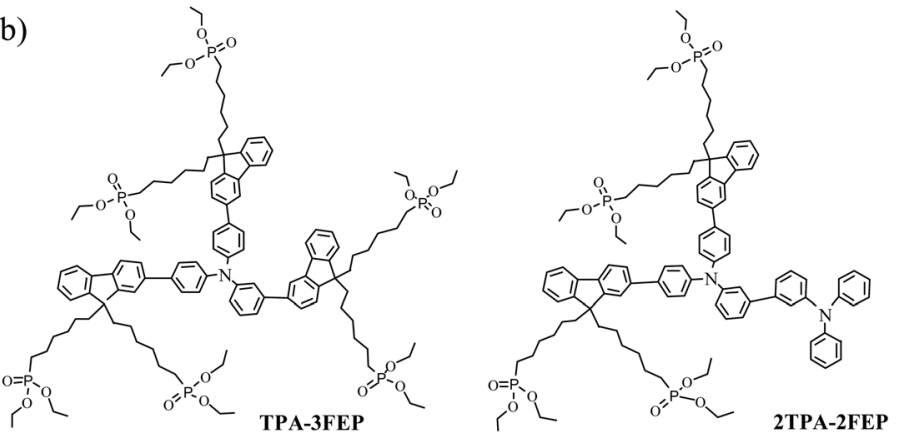

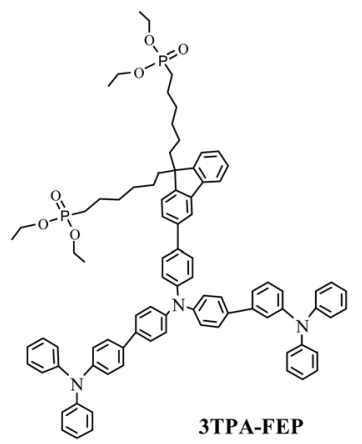

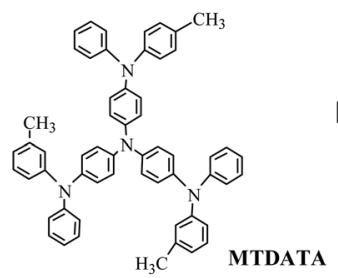

Rhodamine 101

Fig. 27 The chemical structure of a range of (a) polymers and (b) small molecules that have been employed as interlayer in OPVs. 
interlayer in the inverted OPV based on PTB7:PC ${ }_{71} \mathrm{BM}$ blend. ${ }^{3}$ Recently, Xia et al. ${ }^{\mathbf{1 8 0}}$ found a non-monotonic variation of device performance that was dependent on the thickness of the PFN interlayer in an inverted OPV containing a PCDTBT:PC ${ }_{71} \mathrm{BM}$ blend. It was found that a higher PCE could be achieved when the thickness of the PFN layer was between 8 and $12 \mathrm{~nm}$. The use of a PFN interlayer has also been found to be an effective approach to improve the efficiency of OPVs made using the low bandgap polymers PCz-DTBTA ${ }^{181}$ and PECz-DTQx. ${ }^{182}$

A number of other interlayer materials (see Fig. 27 for the molecular structure of these materials) have been used with D-A polymer:fullerene blends to good effect. Yang et al. ${ }^{\mathbf{1 8 3}}$ demonstrated an increase in PCE from $6.1 \%$ to $8.4 \%$ by inserting a PFN-Br polyelectrolyte layer between a $\mathrm{ZnO}$ cathode and a PBDT-DTNT:PC ${ }_{71} \mathrm{BM}$ active layer in an inverted device. The inclusion of the interfacial PFN-Br layer was believed to provide good interfacial contact and adhesion, to facilitate electron transport and to suppress bimolecular recombination, leading to an increased $V_{\mathrm{oc}}, J_{\mathrm{sc}}$ and FF. ${ }^{\mathbf{1 8 4}}$ PFNBR and PSFNBr have been found to improve the performance of OPVs based on PFOTBT:PC ${ }_{61} \mathrm{BM}^{\mathbf{1 8 5}}$ Cationic conjugated polymer electrolytes such as P3TMAHT, PF2/6- $b$-P3TMAHT have also been shown to improve the efficiency of PCDTBT:PC ${ }_{71} \mathrm{BM}$ OPVs when they are incorporated as a OPV interlayer. ${ }^{186}$ The use of a uncharged conjugated polymer (PFPA-1) was reported as an interlayer between a TQ1: $\mathrm{PC}_{71} \mathrm{BM}$ active layer and $\mathrm{a} \mathrm{TiO}_{x} / \mathrm{Al}$ cathode. Here the PFPA-1 layer was believed to act as a hole-blocking layer and also to modify the substrate surface energy and generate a finer morphology in the active layer. ${ }^{187} \mathrm{~A}$ homopolymer of 2,7-carbazole with hydrophilic phosphonate side chains (PC-P) was used as an interlayer on ITO, and was reported to improve the PCE of OPVs made from PCDTBT12 from 5.53\% to $6.04 \% .{ }^{188}$ It was proposed that the hydrophilic side chains of PC-P introduced a sub-gap state that facilitated electron transport. TFB has been incorporated between the hole-transporting layer and the active layer in OPV devices to improve device performance via its electron-blocking ability. ${ }^{\mathbf{1 8 9 , 1 9 0}}$

The saturated polymer poly(ethylene oxide) (PEO) deposited on the electrode $\mathrm{ZnO}$ was found to improve device performance of OPVs made from TQ1 and PCDTBT. PEO was believed to modify the ZnO by passivating surface traps, suppressing charge recombination, reducing device series resistance and improving the electrical coupling between $\mathrm{ZnO}$ and the active layer. ${ }^{191}$ Zhou et al. ${ }^{192}$ reported that an ultrathin polymer layer containing simple aliphatic amine groups (such as PEIE or PEI) that is physisorbed onto a conductor surface (e.g. a metal, metal oxide, conducting polymer, graphene etc.) can act as a "universal" surface modifier to create low-work function electrodes for organic electronics. Chen et al. ${ }^{193}$ have developed a new family of neutral alcohol-soluble small organic molecules as the cathode interlayer (namely 3TPA-FEP, 2TPA-2FEP and TPA-3FEP) that comprise of electron-rich triphenylamine (TPA) and fluorine that are decorated with phosphonate side chains (FEP). A high PCE of $7.21 \%, 6.90 \%$ and $6.89 \%$ was achieved in PCDTBT:PC ${ }_{71} \mathrm{BM}$ devices using 3TPA-FEP, 2TPA-2FEP and TPA-3FEP respectively positioned between $\mathrm{Al}$ and the active layer. Such PCEs are among the highest reported for OPVs based on this particular blend. Other work has demonstrated that small organic molecules such as MTDATA ${ }^{\mathbf{1 9 4}}$ and Rhodamine 101 (ref. 195) can also be successfully applied as interlayers in OPVs containing D-A copolymers.

\section{Summary and outlook}

The donor-acceptor concept provides a facile approach to tune the physical and optoelectronic properties of donor-acceptor copolymers as the electron-donating component in organic photovoltaic devices. Many novel donor-acceptor copolymers have been synthesized in the past few years, and have promoted a rapid development of high performance bulk heterojunction organic solar cells. Power conversion efficiencies above $10 \%$ have now been demonstrated in organic bulk heterojunction solar cells using these D-A materials. As we have described here, several strategies exist to synthesize D-A copolymers having relatively low optical band-gaps, favorable energy levels and ICT characteristics though the rational choice of donor and acceptor moieties, substitution units, branching units and the size and position of solubilizing sidegroups. We have also shown that the application of novel donor-acceptor copolymers in the creation of high performance solar cells requires the formation of a nanoscale morphology and optoelectronic properties that favor absorption of sunlight, exciton splitting and charge-carrier collection processes. Various morphological probes (e.g. high resolution TEM and energy filtered TEM) and scattering techniques (e.g. $\mathrm{X}$-ray scattering, neutron scattering) have been employed to explore the nanoscale morphology in bulk heterojunction blends (e.g. molecular packing and ordering, nanoscale aggregation, 3D connectivity, etc.). Such morphological investigations - in both lateral and vertical directions - have been used to correlate various processing conditions with device performance, and ultimately provide feedback to synthetic chemists in the design of new polymer donors.

Whilst the past few years has evidenced a rapid increase in the efficiency of organic solar cells, there are still many challenges to be met in translating laboratory-scale demonstrations into practical applications. These challenges include increasing device stability and lifetime, the scale up from small-scale to large-scale using solution-based deposition processes such as roll-to-roll production, spray coating and inkjet printing. Such challenges will clearly require close, interdisciplinary collaboration between chemists, physicists and engineers having a direct interest in thin-film manufacturing techniques.

\section{Acknowledgements}

We thank financial support from EPSRC via grant EP/I028641/1 "Polymer/fullerene photovoltaic devices: new materials and innovative processes for high-volume manufacture" and EP/ J017361/1 "Supersolar Solar Energy Hub". AJP thanks King Abdulaziz University for financial support via grant no. D-004/ 431. We thank Lucy Pickford (Ossila Limited, UK) for preparing the TOC image of this paper. 


\section{References}

1 G. Dennler, M. C. Scharber and C. J. Brabec, Adv. Mater., 2009, 21, 1323.

2 P. W. M. Blom, V. D. Mihailetchi, L. J. A. Koster and D. E. Markov, Adv. Mater., 2007, 19, 1551.

3 Z. He, C. Zhong, S. Su, M. Xu, H. Wu and Y. Cao, Nat. Photonics, 2012, 6, 591.

4 J. You, L. Dou, K. Yoshimura, T. Kato, K. Ohya, T. Moriarty, K. Emery, C.-C. Chen, J. Gao, G. Li and Y. Yang, Nat. Commun., 2013, 4, 1446.

5 L. Bian, E. Zhu, J. Tang, W. Tang and F. Zhang, Prog. Polym. Sci., 2012, 37, 1292.

6 C. H. Duan, F. Huang and Y. Cao, J. Mater. Chem., 2012, 22, 10416.

7 H. X. Zhou, L. Q. Yang and W. You, Macromolecules, 2012, 45, 607.

8 M. Mayukh, I. H. Jung, F. He and L. Yu, J. Polym. Sci., Part B: Polym. Phys., 2012, 50, 1057.

9 P.-L. T. Boudreault, A. Najari and M. Leclerc, Chem. Mater., 2011, 23, 456.

10 J. Rivnay, S. C. B. Mannsfeld, C. E. Miller, A. Salleo and M. F. Toney, Chem. Rev., 2012, 112, 5488.

11 D. M. Delongchamp, R. J. Kline and A. Herzing, Energy Environ. Sci., 2012, 5, 5980.

12 W. Chen, M. P. Nikiforov and S. B. Darling, Energy Environ. Sci., 2012, 5, 8045.

13 T. Wang, A. D. F. Dunbar, P. A. Staniec, A. J. Pearson, P. E. Hopkison, J. E. Macdonald, S. Lilliu, C. Pizzey, N. J. Terrill, A. M. Donald, A. J. Ryan, R. A. L. Jones and D. G. Lidzey, Soft Matter, 2010, 6, 4128.

14 B. Schmidt-Hansberg, M. Sanyal, M. F. G. Klein, M. Pfaff, N. Schnabel, S. Jaiser, A. Vorobiev, E. Müller, A. Colsmann, P. Scharfer, D. Gerthsen, U. Lemmer, E. Barrena and W. Schabel, ACS Nano, 2011, 5, 8579.

15 A. J. Pearson, T. Wang and D. G. Lidzey, Rep. Prog. Phys., 2013, 76, 022501.

16 T. Wang, A. J. Pearson, R. A. L. Jones and D. G. Lidzey, Adv. Funct. Mater., 2011, 21, 1383.

17 T. Agostinelli, S. Lilliu, J. G. Labram, M. Campoy-Quiles, M. Hampton, E. Pires, J. Rawle, O. Bikondoa, D. D. C. Bradley, T. D. Anthopoulos, J. Nelson and J. E. Macdonald, Adv. Funct. Mater., 2011, 21, 1701.

18 S. Lilliu, T. Agostinelli, E. Pires, M. Hampton, J. Nelson and J. E. Macdonald, Macromolecules, 2011, 44, 2725.

19 E. Verploegan, C. E. Miller, K. Schmidt, Z. Bao and M. F. Toney, Chem. Mater., 2012, 24, 3923.

20 I. Osaka, M. Shimawaki, H. Mori, I. Doi, E. Miyazaki, T. Koganezawa and K. Takimiya, J. Am. Chem. Soc., 2012, 134, 3498.

21 J.-M. Jiang, P.-A. Yang, T.-H. Hsieh and K.-H. Wei, Macromolecules, 2011, 44, 9155.

22 G.-Y. Chen, Y.-H. Cheng, Y.-J. Chou, M.-S. Su, C.-M. Chen and K.-H. Wei, Chem. Commun., 2011, 47, 5064.

23 J.-M. Jiang, M.-C. Yuan, K. Dinakaran, A. Hariharan and K.-H. Wei, J. Mater. Chem. A, 2013, 1, 4415.
24 M.-S. Su, C.-Y. Kuo, M.-C. Yuan, U.-S. Jeng, C.-J. Su and K. H. Wei, Adv. Mater., 2011, 23, 3315.

25 H.-H. Cho, T. E. Kang, K.-H. Kim, H. Kang, H. J. Kim and B. J. Kim, Macromolecules, 2012, 45, 6415.

26 J. Guo, Y. Liang, J. Szarko, B. Lee, H. J. Son, B. S. Rolczynski, L. Yu and L. X. Chen, J. Phys. Chem. B, 2010, 114, 742.

27 J. M. Szarko, J. Guo, B. S. Rolczynski and L. X. Chen, J. Mater. Chem., 2011, 21, 7849.

28 Y. Liang, Y. Wu, D. Feng, S.-T. Tsai, H.-J. Son, G. Li and L. Yu, J. Am. Chem. Soc., 2009, 131, 56.

29 J. Peet, A. J. Heeger and G. C. Bazan, Acc. Chem. Res., 2009, 42, 1700 .

30 B. C. Thompson and J. M. J. Frechet, Angew. Chem., Int. Ed., 2008, 47, 58.

31 N. D. Treat, M. A. Brady, G. Smith, M. F. Toney, E. J. Kramer, C. J. Hawker and M. L. Chabinyc, Adv. Energy Mater., 2011, 1,82 .

32 A. C. Mayer, M. F. Toney, S. R. Scully, J. Rivnay, C. J. Brabec, M. Scharber, M. Koppe, M. Heeey, I. McCulloch and M. D. McGehee, Adv. Funct. Mater., 2009, 19, 1173.

33 R. Noriega, J. Rivnay, K. Vandewal, F. P. V. Koch, N. Stingelin, P. Smith, M. F. Toney and A. Salleo, Nat. Mater., 2013, DOI: 10.1038/nmat3722.

34 B. A. Collins, Z. Li, J. R. Tumbleston, E. Gann, C. R. McNeill and H. Ade, Adv. Energy Mater., 2012, 3, 65.

35 P. Sista, B. Xue, M. Wilson, N. Holmes, R. S. Kularatne, H. Nguyen, P. C. Dastoor, W. Belcher, K. Poole, B. G. Janesko, M. C. Biewer and M. C. Stefan, Macromolecules, 2012, 45, 772.

36 F. C. Jamieson, E. B. Domingo, T. McCarthy-Ward, M. Heeney, N. Stingelin and J. R. Durrant, Chem. Sci., 2012, 3, 485.

37 P. Westacott, J. R. Tumbleston, S. Shoaee, S. Fearn, J. H. Bannock, J. B. Gilchrist, S. Heutz, J. deMello, M. Heeney, H. Ade, J. Durrant, D. S. McPhail and N. Stingelin, Energy Environ. Sci., 2013, 6, 2756.

38 M. C. Scharber, D. Mühlbacher, M. Koppe, P. Denk, C. Waldauf, A. J. Heeger and C. L. Brabec, Adv. Mater., 2006, 18, 789.

39 J.-L. Brédas, D. Beljonne, V. Coropceanu and J. Cornil, Chem. Rev., 2004, 104, 4971.

40 Y. Li, Acc. Chem. Res., 2012, 45, 723.

41 Z.-G. Zhang, J. Min, S. Zhang, J. Zhang, M. Zhang and Y. Li, Chem. Commun., 2011, 47, 9474.

42 R. Mondal, S. Ko, E. Verploegen, H. A. Becerril, M. F. Toney and Z. Bao, J. Mater. Chem., 2011, 21, 1537.

43 D. H. Kim, A. L. Ayzner, A. L. Appleton, K. Schmidt, J. Mei, M. F. Toney and Z. Bao, Chem. Mater., 2013, 25, 431.

44 T.-Y. Chu, J. Lu, S. Beaupre, Y. Zhang, J.-R. Pouliot, J. Zhou, A. Najari, M. Leclerc and Y. Tao, Adv. Funct. Mater., 2012, 22, 2345.

45 Z. Li, S.-W. Tsang, X. Du, L. Scoles, G. Robertson, Y. Zhang, F. Toll, Y. Tao, J. Lu and J. Ding, Adv. Funct. Mater., 2011, 21, 3331.

46 A. T. Yiu, P. M. Beaujuge, O. P. Lee, C. H. Woo, M. F. Toney and J. M. J. Frechet, J. Am. Chem. Soc., 2012, 134, 2180. 
47 C. Cabanetos, A. E. Labban, J. A. Bartelt, J. D. Douglas, W. R. Mateker, J. M. J. Fréchet, M. D. McGehee and P. M. Beaujuge, J. Am. Chem. Soc., 2013, 135, 4656.

48 J. M. Szarko, J. Guo, Y. Liang, B. Lee, B. S. Rolczynski, J. Strzalka, T. Xu, S. Loser, T. J. Marks, L. Yu and L. X. Chen, Adv. Mater., 2010, 22, 5468.

49 Y. Li, Y. Chen, X. Liu, Z. Wang, X. Yang, Y. Tu and X. Zhu, Macromolecules, 2011, 44, 6370.

50 L. Huo, J. Hou, S. Zhang, H.-Y. Chen and Y. Yang, Angew. Chem., Int. Ed., 2010, 49, 1500.

51 L. Huo, X. Guo, S. Zhang, Y. Li and J. Hou, Macromolecules, 2011, 44, 4035.

52 M. Wang, X. Hu, P. Liu, W. Li, X. Gong, F. Huang and Y. Cao, J. Am. Chem. Soc., 2011, 133, 9638.

53 L. Huo, S. Zhang, X. Guo, F. Xu, Y. Li and J. Hou, Angew. Chem., Int. Ed., 2011, 50, 9697.

54 Y. Huang, X. Guo, F. Liu, L. Huo, Y. Chen, T. P. Russell, C. C. Han, Y. Li and J. Hou, Adv. Mater., 2012, 24, 3383.

55 P. M. Oberhumer, Y.-S. Huang, S. Massip, D. T. James, G. Tu, S. Albert-Seifried, D. Beljonne, J. Cornil, J.-S. Kim, W. T. S. Huck, N. C. Greenham, J. M. Hodgkiss and R. H. Friend, J. Chem. Phys., 2011, 134, 114901.

56 Q. Shi, H. Fan, Y. Liu, J. Chen, L. Ma, W. Hu, Z. Shuai, Y. Li and X. Zhan, Macromolecules, 2011, 44, 4230.

57 E. Wang, M. Wang, L. Wang, C. Duan, J. Zhang, W. Cai, C. He, H. Wu and Y. Cao, Macromolecules, 2009, 42, 4410.

58 S. K. Lee, S. Cho, M. Tong, J. H. Seo and A. J. Heeger, J. Polym. Sci., Part A: Polym. Chem., 2011, 49, 1821.

$59 \mathrm{H}$. Zhou, L. Yang, S. Xiao, S. Liu and W. You, Macromolecules, 2010, 43, 811.

60 A. A. El-Shehawy, N. I. Abdo, A. A. El-Barbary and J.-S. Lee, Eur. J. Org. Chem., 2011, 25, 4841.

61 Y. Li, Y. Fu, H. Tong, Z. Xie and L. Wang, J. Polym. Sci., Part A: Polym. Chem., 2013, 51, 2910.

62 C. H. Woo, P. M. Beaujuge, T. W. Holcombe, O. P. Lee and J. M. J. Frechet, J. Am. Chem. Soc., 2010, 132, 15547.

63 S. Shi, P. Jiang, S. Chen, Y. Sun, X. Wang, K. Wang, S. Shen, X. Li, Y. Li and H. Wang, Macromolecules, 2012, 45, 7806.

64 X. Wang, Y. Sun, S. Chen, X. Guo, M. Zhang, X. Li, Y. Li and H. Wang, Macromolecules, 2012, 45, 1208.

65 W.-H. Lee, S. K. Son, K. Kim, S. K. Lee, W. S. Shin, S.-J. Moon and I.-N. Kang, Macromolecules, 2012, 45, 1303.

66 H.-Y. Chen, S.-C. Yeh, C.-T. Chen and C.-T. Chen, J. Mater. Chem., 2012, 22, 21549.

67 M. Shahid, R. S. Ashraf, Z. Huang, A. J. Kronemeijer, T. McCarthy-Ward, I. McCulloch, J. R. Durrant, H. Sirringhaus and M. Heeney, J. Mater. Chem., 2012, 22, 12817.

68 J. S. Ha, K. H. Kim and D. H. Choi, J. Am. Chem. Soc., 2011, 133, 10364.

69 A. J. Kronemeijer, E. Gili, M. Shahid, J. Rivnay, A. Salleo, M. Heeney and H. Sirringhaus, Adv. Mater., 2012, 24, 1558.

70 M. Shahid, T. McCarthy-Ward, J. Labram, S. Rossbauer, E. B. Domingo, S. E. Watkins, N. Stingelin, T. D. Anthopoulos and M. Heeney, Chem. Sci., 2012, 3, 181.

71 H. A. Saadeh, L. Lu, F. He, J. E. Bullock, W. Wang, B. Carsten and L. Yu, ACS Macro Lett., 2012, 1, 361.
72 L. Dou, W.-H. Chang, J. Gao, C.-C. Chen, J. You and Y. Yang, Adv. Mater., 2013, 25, 825.

73 A. A. B. Alghamdi, D. C. Watters, H. Yi, S. Al-Faifi, M. S. Almeataq, D. Coles, J. Kingsley and D. G. Lidzey, J. Mater. Chem. A, 2013, 1, 5165.

74 J.-S. Wu, Y.-J. Cheng, T.-Y. Lin, C.-Y. Chang, P.-I. Shih and C.-S. Hsu, Adv. Funct. Mater., 2012, 22, 1711.

75 J.-M. Jiang, P.-A. Yang, C.-M. Yu, H.-K. Lin, K.-C. Huang and K.-H. Wei, J. Polym. Sci., Part A: Polym. Chem., 2012, 50, 3960.

76 M. C. Scharber, M. Koppe, J. Gao, F. Cordella, M. A. Loi, P. Denk, M. Morana, H.-J. Egelhaaf, K. Forberich, G. Dennler, R. Gaudiana, D. Waller, Z. Zhu, X. Shi and C. J. Brabec, Adv. Mater., 2010, 22, 367.

77 H.-Y. Chen, J. Hou, A. E. Hayden, H. Yang, K. N. Houk and Y. Yang, Adv. Mater., 2010, 22, 371.

78 J. H. Hou, H. Y. Chen, S. Q. Zhang, G. Li and Y. Yang, J. Am. Chem. Soc., 2008, 130, 16144.

79 J. Peet, J. Y. Kim, N. E. Coates, W. L. Ma, D. Moses, A. J. Heeger and G. C. Bazan, Nat. Mater., 2007, 6, 497.

80 D. Gendron, P.-O. Morin, P. Berrouard, N. Allard, B. R. Aich, C. N. Garon, Y. Tao and M. Leclerc, Macromolecules, 2011, 44, 7188.

81 J. S. Kim, Z. Fei, D. T. James, M. Heeney and J.-S. Kim, J. Mater. Chem., 2012, 22, 9975.

82 Y. Zhang, J. Zou, H.-L. Yip, Y. Sun, J. A. Davies, K.-S. Chen, O. Acton and A. K.-Y. Jen, J. Mater. Chem., 2011, 21, 3895.

83 J.-S. Wu, Y.-Y. Lai, Y.-J. Cheng, C.-Y. Chang, C.-L. Wang and C.-S. Hsu, Adv. Energy Mater., 2013, 3, 457.

84 N. Blouin, A. Michaud, D. Gendron, S. Wakim, E. Blair, R. Neagu-Plesu, M. Belletete, G. Durocher, Y. Tao and M. Leclerc, J. Am. Chem. Soc., 2008, 130, 732.

85 C. V. Hoven, X.-D. Dang, R. C. Coffin, J. Peet, T.-Q. Nguyen and G. C. Bazan, Adv. Mater., 2010, 22, E63.

86 J. C. Bijleveld, M. Shahid, J. Gilot, M. M. Wienk and R. A. J. Janssen, Adv. Funct. Mater., 2009, 19, 3262.

87 H. Bronstein, J. M. Frost, A. Hadipour, Y. Kim, C. B. Nielsen, R. S. Ashraf, B. P. Rand, S. Watkins and I. McCulloch, Chem. Mater., 2013, 25, 277.

88 H.-Y. Chen, J. Hou, S. Zhang, Y. Liang, G. Yang, Y. Yang, L. Yu, Y. Wu and G. Li, Nat. Photonics, 2009, 3, 649.

89 S. C. Price, A. C. Stuart, L. Yang, H. Zhou and W. You, J. Am. Chem. Soc., 2011, 133, 4625.

90 F. Babudri, G. M. Farinola, F. Naso and R. Ragni, Chem. Commun., 2007, 1003.

91 L. Yang, J. R. Tumbleston, H. Zhou, H. Ade and W. You, Energy Environ. Sci., 2013, 6, 316.

92 Y. Zhang, S.-C. Chien, K.-S. Chen, H.-L. Yip, Y. Sun, J. A. Davies, F.-C. Chen and A. K. Y. Jen, Chem. Commun., 2011, 47, 11026.

93 Z. Li, J. Lu, S.-C. Tse, J. Zhou, X. Du, Y. Tao and J. Ding, J. Mater. Chem., 2011, 21, 3226.

94 H. Zhou, L. Yang, A. C. Stuart, S. C. Price, S. Liu and W. You, Angew. Chem., Int. Ed., 2011, 50, 2995.

95 S. Albrecht, S. Janietz, W. Schindler, J. Frisch, J. Kurpiers, J. Kniepert, S. Inal, P. Pingel, K. Fostiropoulos, N. Koch and D. Neher, J. Am. Chem. Soc., 2012, 134, 14932. 
96 A. C. Stuart, J. R. Tumbleston, H. Zhou, W. Li, S. Liu, H. Ade and W. You, J. Am. Chem. Soc., 2013, 135, 1806.

97 H. J. Son, W. Wang, T. Xu, Y. Liang, Y. Wu, G. Li and L. Yu, J. Am. Chem. Soc., 2011, 133, 1885.

98 M. Lenes, G. J. A. H. Wetzelaer, F. B. Kooistra, S. C. Veenstra, J. C. Hummelen and P. W. M. Blom, Adv. Mater., 2008, 20, 2116.

99 M. Lenes, S. W. Shelton, A. B. Sieval, D. F. Kronholm, J. C. Hummelen and P. W. M. Blom, Adv. Funct. Mater., 2009, 19, 3002.

100 Y. J. He, H. Y. Chen, J. H. Hou and Y. F. Li, J. Am. Chem. Soc., 2010, 132, 1377.

101 Y. J. He, J. B. You, L. T. Dou, C. C. Chen, E. Richard, K. C. Cha, Y. Wu, G. Li and Y. Yang, Chem. Commun., 2012, 48, 7616.

102 Y. J. He, C. C. Chen, E. Richard, L. T. Dou, Y. Wu, G. Li and Y. Yang, J. Mater. Chem., 2011, 22, 13391.

103 R. B. Ross, C. M. Cardona, D. M. Guldi, S. G. Sankaranarayanan, M. O. Reese, N. Kopidakis, J. Peet, B. Walker, G. C. Bazan, E. Van Keuren, B. C. Holloway and M. Drees, Nat. Mater., 2009, 8, 208.

104 M. A. Faist, P. E. Keivanidis, S. Foster, P. H. Wobkenberg, T. D. Anthopoulos, D. D. C. Bradley, J. R. Durrant and J. Nelson, J. Polym. Sci., Part B: Polym. Phys., 2011, 49, 45.

105 A. A. Y. Guilbert, L. X. Reynolds, A. Bruno, A. MacLachlan, S. P. King, M. A. Faist, E. Pires, J. E. Macdonald, N. Stingelin, S. A. Haque and J. Nelson, ACS Nano, 2012, 6, 3868 .

106 H. Kang, C. H. Cho, H. H. Cho, T. E. Kang, H. J. Kim, K. H. Kim, S. C. Yoon and B. J. Kim, ACS Appl. Mater. Interfaces, 2012, 4, 110.

107 G. J. Zhao, Y. J. He and Y. F. Li, Adv. Mater., 2010, 22, 4355.

108 H. Xin, S. Subramaniyan, T. W. Kwon, S. Shoaee, J. R. Durrant and S. A. Jenekhe, Chem. Mater., 2012, 24, 1995.

109 R. C. I. MacKenzie, J. M. Frost and J. Nelson, J. Chem. Phys., 2010, 132, 064904.

110 M. A. Faist, T. Kirchartz, W. Gong, R. S. Ashraf, I. McCulloch, J. C. de Mello, N. J. Ekins-Daukes, D. D. C. Bradley and J. Nelson, J. Am. Chem. Soc., 2012, 134, 685.

111 J. H. Huang, Y. S. Hsiao, E. Richard, C. C. Chen, P. L. Chen, G. Li, C. W. Chu and Y. Yang, Appl. Phys. Lett., 2013, 103, 043304.

112 N. C. Cates, R. Gysel, Z. Beiley, C. E. Miller, M. F. Toney, M. Heeney, I. McCulloch and M. D. McGehee, Nano Lett., 2009, 9, 4153.

113 N. C. Miller, S. Sweetnam, E. T. Hoke, R. Gysel, C. E. Miller, J. A. Bartelt, X. X. Xie, M. F. Toney and M. D. McGehee, Nano Lett., 2012, 12, 1566.

114 N. C. Miller, E. Cho, M. J. N. Junk, R. Gysel, C. Risko, D. Kim, S. Sweetnam, C. E. Miller, L. J. Richter, R. J. Kline, M. Heeney, I. McCulloch, A. Amassian, D. Acevedo-Feliz, C. Knox, M. R. Hansen, D. Dudenko, B. F. Chmelka, M. F. Toney, J. L. Bredas and M. D. McGehee, Adv. Mater., 2012, 24, 6071.
115 N. C. Miller, E. Cho, R. Gysel, C. Risko, V. Coropceanu, C. E. Miller, S. Sweetnam, A. Sellinger, M. Heeney, I. McCulloch, J. L. Bredas, M. F. Toney and M. D. McGehee, Adv. Energy Mater., 2012, 2, 1208.

116 M. Koppe, H. J. Egelhaaf, G. Dennler, M. C. Scharber, C. J. Brabec, P. Schilinsky and C. N. Hoth, Adv. Funct. Mater., 2010, 20, 338.

117 P. P. Khlyabich, B. Burkhart and B. C. Thompson, J. Am. Chem. Soc., 2012, 134, 9074.

118 R. A. Street, D. Davies, P. P. Khlyabich, B. Burkhart and B. C. Thompson, J. Am. Chem. Soc., 2013, 135, 986.

119 J.-H. Huang, M. Velusamy, K.-C. Ho, J.-T. Lin and C.-W. Chu, J. Mater. Chem., 2010, 20, 2820.

120 D. Deribew, E. Pavlopoulou, G. Fleury, C. Nicolet, C. Renaud, S.-J. Mougnier, L. Vignau, E. Cloutet, C. Brochon, F. Cousin, G. Portale, M. Geoghegan and G. Hadziioannou, Macromolecules, 2013, 46, 3015.

121 S. J. Park, J. M. Cho, W.-B. Byun, J.-C. Lee, W. S. Shin, I.-N. Kang, S.-J. Moon and S. K. Lee, J. Polym. Sci., Part A: Polym. Chem., 2011, 49, 4416.

122 T. Ameri, P. Khoram, J. Min and C. J. Brabec, Adv. Mater., 2013, 25, 4245.

123 L. Yang, L. Yan and W. You, J. Phys. Chem. Lett., 2013, 4, 1802.

124 Y.-C. Chen, C.-Y. Hsu, R. Y.-Y. Lin, K.-C. Ho and J. T. Lin, ChemSusChem, 2013, 6, 20.

125 H.-Y. Chen, J. Hou, A. E. Hayden, H. Yang, K. N. Houk and Y. Yang, Adv. Mater., 2010, 22, 371.

126 H. Y. Lu, B. Akgun and T. P. Rusell, Adv. Energy Mater., 2011, 1, 870.

127 J. A. Bartelt, Z. M. Beiley, E. T. Hoke, W. R. Mateker, J. D. Douglas, B. A. Collins, J. R. Tumbleston, K. R. Graham, A. Amassian, H. Ade, J. M. J. Fréchet, M. F. Toney and M. D. McGehee, Adv. Energy Mater., 2013, 3, 364 .

128 Z. M. Beiley, E. T. Hoke, R. Noriega, J. Dacuna, G. F. Burkhard, J. A. Bartelt, A. Salleo, M. F. Toney and M. D. McGehee, Adv. Energy Mater., 2011, 1, 954.

129 T. Wang, A. J. Pearson, A. D. F. Dunbar, P. A. Staniec, D. C. Watters, D. Coles, H. Yi, A. Iraqi, D. G. Lidzey and R. A. L. Jones, Eur. Phys. J. E: Soft Matter Biol. Phys., 2012, 35, 129.

130 X. H. Lu, H. Hlaing, D. S. Germack, J. Peet, W. H. Jo, D. Andrienko, K. Kremer and B. M. Ocko, Nat. Commun., 2012, 3, 795.

131 T. Wang, A. J. Pearson, A. D. F. Dunbar, P. A. Staniec, D. C. Watters, H. Yi, A. J. Ryan, R. A. L. Jones, A. Iraqi and D. G. Lidzey, Adv. Funct. Mater., 2012, 22, 1399.

132 J. C. Guo, Y. Y. Liang, J. Szarko, B. Lee, H. J. Son, B. S. Rolczynski, L. P. Yu and L. X. Chen, J. Phys. Chem. B, 2010, 114, 742.

133 J. F. Lee, S. L.-C. Hsu, P.-I. Lee, H.-Y. Chuang, J.-S. Chen and W.-Y. Chou, J. Polym. Sci., Part A: Polym. Chem., 2011, 49, 4618.

134 Q. Zheng, G. Fang, R. C. Coffin, C. M. MacNeill, Y. Li, N. Sun, P. Qin, W. Nie, E. D. Peterson, X. Fan, F. Cheng, H. Huang, M. Wang, X. Zhao and D. Carroll, Sol. Energy Mater. Sol. Cells, 2011, 95, 3114. 
135 S. H. Park, A. Roy, S. Beaupré, S. Cho, N. Coates, J. S. Moon, D. Moses, M. Leclerc, K. Lee and A. J. Heeger, Nat. Photonics, 2009, 3, 297.

136 S. Alem, T.-Y. Chu, S. C. Tse, S. Wakima, J. Lu, R. Movileanu, Y. Tao, F. Bélanger, D. Désilets, S. Beaupré, M. Leclerc, S. Rodman, D. Waller and R. Gaudiana, Org. Electron., 2011, 12, 1788.

137 L. Ye, S. Zhang, W. Ma, B. Fan, X. Guo, Y. Huang, H. Ade and J. Hou, Adv. Mater., 2012, 24, 6335.

138 F. Liu, Y. Gu, C. Wang, W. Zhao, D. Chen, A. L. Briseno and T. P. Russell, Adv. Mater., 2012, 24, 3947.

139 Y. Yao, J. Hou, Z. Xu, G. Li and Y. Yang, Adv. Funct. Mater., 2008, 18, 1783.

140 D. Muhlbacher, M. Scharber, M. Morana, Z. G. Zhu, D. Waller, R. Gaudiana and C. J. Brabec, Adv. Mater., 2006, 18, 2931.

141 Z. Zhu, D. Waller, R. Gaudiana, M. Morana, D. Muhlbacher, M. Scharber and C. Brabec, Macromolecules, 2007, 40, 1981.

142 T.-Y. Chu, J. Lu, S. Beaupre, Y. Zhang, J.-R. Pouliot, S. Wakim, J. Zhou, M. Leclerc, Z. Li, J. Ding and Y. Tao, J. Am. Chem. Soc., 2011, 133, 4250.

143 J. T. Roger, K. Schmidt, M. F. Toney, E. J. Kramer and G. C. Bazan, Adv. Mater., 2011, 23, 2284.

144 J. K. Lee, W. L. Ma, C. J. Brabec, J. Yuen, J. S. Moon, J. Y. Kim, K. Lee, G. C. Bazan and A. J. Heeger, J. Am. Chem. Soc., 2008, 130, 3619.

145 Y. Liang, X. Zheng, J. Xia, S.-T. Tsai, Y. Wu, G. Li, C. Ray and L. Yu, Adv. Mater., 2010, 22, E135.

146 J. Peet, J. Y. Kim, N. E. Coates, W. L. Ma, D. Moses, A. J. Heeger and G. C. Bazan, Nat. Mater., 2007, 6, 497.

147 C. V. Hoven, X. D. Dang, R. C. Coffin, J. Peet, T. Q. Nguyen and G. C. Bazan, Adv. Mater., 2010, 22, E63.

148 J. C. Bijleveld, V. S. Gevaerts, D. D. Nuzzo, M. Turbiez, S. G. J. Mathijssen, D. M. de Leeuw, M. M. Wienk and R. A. J. Janssen, Adv. Mater., 2010, 22, E242.

149 C. M. Amb, S. Chen, K. R. Graham, J. Subbiah, C. E. Small, F. So and J. R. Reynolds, J. Am. Chem. Soc., 2011, 133, 10062.

150 B. A. Collins, Z. Li, J. R. Tumbleston, E. Gann, C. R. McNeill and H. Ade, Adv. Energy Mater., 2013, 3, 65.

151 S. J. Lou, J. M. Szarko, T. Xu, L. Yu, T. J. Marks and L. X. Chen, J. Am. Chem. Soc., 2011, 133, 20661.

152 Y. Gu, C. Wang and T. P. Russell, Adv. Energy Mater., 2012, 2, 683 .

153 J. T. Rogers, K. Schmidt, M. F. Toney, G. C. Bazan and E. J. Kramer, J. Am. Chem. Soc., 2012, 134, 2884.

154 T. Agostinelli, T. A. M. Ferenczi, E. Pires, S. Foster, A. Maurano, C. Müller, A. Ballantyne, M. Hampton, S. Lilliu, M. Campoy-Quiles, H. Azimi, M. Morana, D. D. C. Bradley, J. Durrant, J. E. Macdonald, N. Stingelin and J. Nelson, J. Polym. Sci., Part B: Polym. Phys., 2011, 23, 2284.

155 C. Piliego, T. W. Holcombe, J. D. Douglas, C. H. Woo, P. M. Beaujuge and J. M. J. Frechet, J. Am. Chem. Soc., 2010, 132, 7595.

156 B. Gholamkhass and P. Servati, Org. Electron., 2013, 14, 2278.

157 J. Liu, L. Chen, B. Gao, X. Cao, Y. Han, Z. Xie and L. Wang, J. Mater. Chem. A, 2013, 1, 6216.
158 A. S. Anselmo, L. Lindgren, J. Rysz, A. Bernasik, A. Budkowski, M. R. Andersson, K. Svensson, J. van Stam and E. Moons, Chem. Mater., 2011, 23, 2295.

159 M. P. Felicissimo, D. Jarzab, M. Gorgoi, M. Forster, U. Scherf, M. C. Scharber, S. Svensson, P. Rudolf and M. A. Loi, J. Mater. Chem., 2009, 19, 4899.

160 P. A. Staniec, A. J. Parnell, A. D. F. Dunbar, H. Yi, A. J. Pearson, T. Wang, P. E. Hopkinson, C. Kinane, R. M. Dalgliesh, A. M. Donald, A. J. Ryan, A. Iraqi, R. A. L. Jones and D. G. Lidzey, Adv. Energy Mater., 2011, 1, 499.

161 H.-J. Liu, U.-S. Jeng, N. L. Yamada, A.-C. Su, W.-R. Wu, C.-J. Su, S.-J. Lin, K.-H. Wei and M.-Y. Chiu, Soft Matter, 2011, 7, 9276.

162 D. S. Germack, C. K. Chan, R. J. Kline, D. A. Fischer, D. J. Gundlach, M. F. Toney, L. J. Richter and D. M. DeLongchamp, Macromolecules, 2010, 43, 3828.

163 T. Wang, N. W. Scarratt, H. Yi, A. D. F. Dunbar, A. J. Pearson, D. C. Watters, T. S. Glen, A. C. Brook, J. Kingsley, A. R. Buckley, M. W. A. Skoda, A. M. Donald, R. A. L. Jones, A. Iraqi and D. G. Lidzey, Adv. Energy Mater., 2013, 3, 505.

164 L. Chang, H. W. A. Lademann, J.-B. Bonekamp, K. Meerholz and A. J. Moulé, Adv. Funct. Mater., 2011, 21, 1779.

165 G. Reiter and P. G. de Gennes, Eur. Phys. J. E: Soft Matter Biol. Phys., 2001, 6, 25.

166 L. Ye, Y. Jing, X. Guo, H. Sun, S. Zhang, M. Zhang, L. Huo and J. Hou, J. Phys. Chem. C, 2013, 117, 14920.

167 Z. Li, H. C. Wong, Z. Huang, H. Zhong, C. H. Tan, W. C. Tsoi, J. S. Kim, J. R. Durrant and J. T. Cabral, Nat. Commun., 2013, 4, 2227.

168 F. Piersimoni, G. Degutis, S. Bertho, K. Vandewal, D. Spoltore, T. Vangerven, J. Drijkoningen, M. K. Van Bael, A. Hardy, J. D'Haen, W. Maes, D. Vanderzande, M. Nesladek and J. Manca, J. Polym. Sci., Part B: Polym. Phys., 2013, 51, 1209.

169 A. Distler, T. Sauermann, H.-J. Egelhaaf, S. Rodman, D. Waller, K.-S. Cheon, M. Lee and D. M. Guldi, Adv. Energy Mater., 2013, DOI: 10.1002/aenm.201300693.

170 Y. Suh, N. Lu, S. H. Lee, W.-S. Chung, K. Kim, B. Kim, M. J. Ko and M. J. Kim, ACS Appl. Mater. Interfaces, 2012, 4, 5118.

171 H. Aziz and Z. D. Popovic, Chem. Phys., 2004, 16, 4522.

172 Y. Sun, C. J. Takacs, S. R. Cowan, J. H. Seo, X. Gong, A. Roy and A. J. Heeger, Adv. Mater., 2011, 23, 2226.

173 M. Jørgensen, K. Norrman, S. A. Gevorgyan, T. Tromholt, B. Andreasen and F. C. Krebs, Adv. Mater., 2012, 24, 580.

174 M. Manceau, E. Bundgaard, J. E. Carlé, O. Hagemann, M. Helgesen, R. Søndergaard, M. Jørgensen and F. C. Krebs, J. Mater. Chem., 2011, 21, 4132.

175 N. Cho, H.-L. Yip, J. A. Davies, P. D. Kazarinoff, D. F. Zeigler, M. M. Durban, Y. Segawa, K. M. O'Malley, C. K. Luscombe and A. K.-Y. Jen, Adv. Energy Mater., 2011, 1, 1148.

176 J. E. Carlé, B. Andreasen, T. Tromholt, M. V. Madsen, K. Norrman, M. Jørgensen and F. C. Krebs, J. Mater. Chem., 2012, 22, 24417.

177 C.-H. Hsieh, Y.-J. Cheng, P.-J. Li, C.-H. Chen, M. Dubosc, R.-M. Liang and C.-S. Hsu, J. Am. Chem. Soc., 2010, 132, 4887. 
178 C. Duan, K. Zhang, C. Zhong, F. Huang and Y. Cao, Chem. Soc. Rev., 2013, DOI: 10.1039/C3CS60200A.

179 Z. He, C. Zhong, X. Huang, W. Y. Wong, H. Wu, L. Chen, S. Su and Y. Cao, Adv. Mater., 2011, 23, 4636.

180 R. Xia, D.-S. Leem, T. Kirchartz, S. Spencer, C. Murphy, Z. He, H. Wu, S. Su, Y. Cao, J. S. Kim, J. C. deMello, D. D. C. Bradley and J. Nelson, Adv. Energy Mater., 2013, 3, 718.

181 L. Zhang, C. He, J. Chen, P. Yuan, L. Huang, C. Zhang, W. Cai, Z. Liu and Y. Cao, Macromolecules, 2010, 43, 9771.

182 Z. He, C. Zhang, X. Xu, L. Zhang, L. Huang, J. Chen, H. Wu and Y. Cao, Adv. Mater., 2011, 23, 3086.

183 T. Yang, M. Wang, C. Duan, X. Hu, L. Huang, J. Peng, F. Huang and X. Gong, Energy Environ. Sci., 2012, 5, 8208.

184 X. Gong, Polymer, 2012, 53, 5437.

185 Y. Che, Z. Jiang, M. Cao, S. E. Watkins, P. Lu, H. Wang and X. Chen, Appl. Phys. Lett., 2012, 100, 203304.

186 J. H. Seo, A. Gutacker, Y. Sun, H. Wu, F. Huang, Y. Cao, U. Scherf, A. J. Heeger and G. C. Bazan, J. Am. Chem. Soc., 2011, 133, 8416.

187 Z. Tang, L. M. Andersson, Z. Georage, K. Vandewal, K. Tvingstedt, P. Heriksson, R. Kroon, M. R. Andersson and O. Inganas, Adv. Mater., 2012, 24, 554.
188 J. Sun, Y. Zhu, X. Xu, L. Lan, L. Zhang, P. Cai, J. Chen, J. Peng and Y. Cao, J. Phys. Chem. C, 2012, 116, 14188.

189 A. W. Hains, J. Liu, A. B. F. Martinson, M. D. Irwin and T. J. Marks, Adv. Funct. Mater., 2010, 20, 595.

190 J. Subbiah, D. Y. Kim, M. Hartel and F. So, Appl. Phys. Lett., 2010, 96, 063303.

191 S. Shao, K. Zheng, T. Pullerits and F. Zhang, ACS Appl. Mater. Interfaces, 2013, 5, 380.

192 Y. Zhou, C. Fuentes-Hernandez, J. Shim, J. Meyer, A. J. Giordano, H. Li, P. Winget, T. Papadopoulos, H. Cheun, J. Kim, M. Fenoll, A. Dindar, W. Haske, E. Najafabadi, T. M. Khan, H. Sojoudi, S. Barlow, S. Graham, J. L. Bredas, S. R. Marder, A. Kahn and B. Kippelen, Science, 2012, 336, 327.

193 D. Chen, H. Zhou, M. Liu, W.-M. Zhao, S.-J. Su and Y. Cao, Macromol. Rapid Commun., 2013, 34, 595.

194 J. Subbiah, C. M. Amb, I. Irfan, Y. Gao, J. R. Reynolds and F. So, ACS Appl. Mater. Interfaces, 2012, 4, 866.

195 K. Sun, B. Zhao, V. Murugesan, A. Kumar, K. Zeng, J. Subbiah, W. W. H. Wong, D. J. Jones and J. Ouyang, J. Mater. Chem., 2012, 22, 24155. 